\title{
Measuring and Interpreting Urban Externalities in Real-Estate Data: A Spatio-Temporal Difference-in-Differences (STDID) Estimator
}

\author{
Jean Dubé ${ }^{1, *}$, Diègo Legros ${ }^{2}$, Marius Thériault ${ }^{1}$ and François Des Rosiers ${ }^{3}$ \\ 1 École supérieure d'aménagement du territoire et de développement régional (ÉSAD), Université Laval, \\ Ville de Québec, QC G1V 0A6, Canada; marius.theriault@esad.ulaval.ca \\ 2 Laboratoire d'Économie de Dijon (LEDi), Université de Bourgogne, 21078 Dijon cedex, France; \\ diego.legros@u-bourgogne.fr \\ 3 Faculté des sciences de l'administration (FSA), Université Laval, Ville de Québec, QC G1V 0A6, Canada; \\ francois.desrosiers@fsa.ulaval.ca \\ * Correspondence: jean.dube@esad.ulaval.ca; Tel.: +1-418-656-2131 (ext. 6763)
}

Received: 24 May 2017; Accepted: 13 June 2017; Published: 16 June 2017

\begin{abstract}
It is now almost impossible to deal with spatial data without considering some explicit specification that captures possible spatial effects. One valuable feature of spatial econometrics models is their decomposition of marginal effects into spatial spillover effect and spatial externalities. Progress in interpreting spatial econometrics models has now been extended to the spatial-panel case. However, little consideration has been given to the possible interpretation of models using spatial data pooled over time. This paper proposes a spatio-temporal difference-in-differences (STDID) estimator to measure the effect of urban externalities, such as transport infrastructures, as revealed through real-estate prices. Based on an empirical application for a new development of commuter trains in the Montreal suburbs, this paper shows how such propositions can help us to better understand and evaluate changes in mass transit systems.
\end{abstract}

Keywords: spatio-temporal data; spatial econometric; marginal effects; difference-in-differences (DID) estimator; mass transit system

\section{Introduction}

Measuring urban externalities is a challenge, notably, in urban economics, economic geography, and transportation. Since development of the hedonic theory [1], many applications have relied on this approach based on revealed preferences to measure willingness-to-pay (WTP) for urban externalities. Hedonic pricing models have been widely applied to real-estate values. Although such an application is fairly straightforward, many challenges remain when it comes to adequately measuring the effect of urban externalities on real-estate values.

Empirical analysis is complicated by the fact that real-estate values clearly display a spatial pattern that directly influences the precise estimation of the effect of the implicit prices of extrinsic amenities on real-estate values. Various techniques have been developed to deal with spatial autocorrelation among residuals, such as geo-statistical techniques [2-4], the coefficient expansion method [5,6], local regression techniques [7-10] and spatial econometric models [11-13].

Spatial econometric models are used increasingly for practical matters-because detection of spatial autocorrelation among residuals can invalidate the conclusions of the estimated models [14,15]—but also for theoretical matters—dealing with spatial heterogeneity, spatial externalities, and spatial spillovers [16]. A clear advantage of spatial econometric models lies in the decomposition of the marginal effect to account for spatial externalities, and of the spatial spillover 
effect, also denoted by local and global spatial effects [17]. Recently, [18] has explicitly presented the best practices related to the use of spatial econometrics in empirical applications. Of course, like any other modelling approach, spatial econometrics is not without its critics (see [19-21]). However, some criticisms, such as the myth behind the effect of the choice of the weights matrix on the sensitivity of results, have recently been demystified [22].

The particularities of real-estate transaction data raise some additional complications when estimating spatial hedonic pricing models. The fact that spatial data are collected (or pooled) over time underlines the importance of taking into account spatial considerations, but also additional constraints relate to temporal unidirectional relations among the observations (transactions) [23]. Although adequate spatio-temporal models have been proposed for such data [24-27] and the difference between the structure of spatio-temporal and spatial weights matrices has been demonstrated [28], not much emphasis has been placed on how to interpret the estimated coefficients of such models. In such a case, the decomposition of the spatial effects into two separate effects-spatial multidirectional effect and spatial unidirectional effect-plainly affect the calculation of the marginal effect.

The aim of the paper is twofold. First, a complete spatio-temporal difference-in-differences (STDID) estimator is proposed to evaluate the impact of urban externalities on real-estate values through a quasi-natural experiment. Second, a complete interpretation of the marginal effects accounting for the fact that the spatial effect can be decomposed into two separate components (multidirectional spatial effect and unidirectional spatial effect) is proposed. One advantage of the paper is that it offers simple formulas with which to retrieve the indirect spatial effect from the total marginal effect for a given time period, and with which to evaluate the short-run and long-run spatial effects. In the end, the interpretation proposed is different from what has usually been suggested, but it clearly facilitates computation and interpretation using multiplication of scalar parameters to evaluate the mean effect, which will surely reduce the misinterpretation of such effects in empirical analysis.

To demonstrate the potential of STDID, it is applied empirically to the development of a new public transit system in the Montreal (Canada) suburban area. On the basis of individual transactions between 1992 and 2009, the model isolates the (exogenous) effect of a change in the mass transit system. Previous work based on difference-in-differences (DID) estimators [29,30] and spatial difference-in-differences (SDID) estimators [31] are revisited and the estimated model shows how the effect on house prices (or house price growth) can induce spatial spillover effects as well as dynamic spatial effects.

The paper is divided into four sections. The first section presents a brief overview of the hedonic pricing model and its extension to spatial econometrics. It also sets out the interpretation related to the calculation of the marginal effects for such models. Particular emphasis is placed on presenting the characteristics and specificities of such models for spatial data pooled over time. The second section presents a variation of the hedonic pricing model based on the repeated-sales approach, which is a natural application of the DID estimator. A natural extension of the estimator based on spatial and spatio-temporal considerations is presented, with special emphasis on the calculation and interpretation of the calculation of the marginal effects. The third section presents the empirical investigation: the data used, the model estimated, and the interpretation of the results. The paper concludes with a summary of the main results and with perspectives for future uses and needs for spatio-temporal econometric models for spatial data pooled over time.

\section{Measuring Urban Externalities with the Hedonic Pricing Model}

\subsection{The Hedonic Pricing Model}

Hedonic pricing theory was formally defined by [1]. Since that pioneering work, many empirical applications relying on hedonic pricing (HP) models have been developed, expressing the statistical relationship between the price of a complex good, $y$, as a function of the individual (intrinsic and extrinsic) amenities that form the bundle describing the real-estate good (Equation (1)). 


$$
\mathbf{y}=\alpha \mathbf{l}+\mathbf{X} \beta+\varepsilon
$$

Whereas the dependent variables are stacked in a vector $\mathbf{y}$ of dimension $(\mathrm{N} \times 1)$, the list of independent variables are stacked in a matrix $\mathbf{X}$ of dimension $(\mathrm{N} \times \mathrm{K}), \mathrm{l}$ is a vector of one, and $\varepsilon$ a vector of errors, both of dimension $(\mathrm{N} \times 1)$. The vector of parameters $\beta$ is designed to evaluate the implicit price of each amenity and is of dimension $(\mathrm{K} \times 1)$, while $\alpha$ is a scalar parameter.

There are many criticisms of this linear representation of the price equation. One such criticism relates to the choice of the functional form of the price equation. According to [32], adopting a poor specification of the functional form can introduce bias into the measurement of the parameters and so invalidate the measurement of the implicit price of the different amenities, even more so if the relation is not linear with respect to the amenities. Of course, this problem can be solved by adopting a more flexible functional form, introducing non-linear variables (mathematical transformations of the independent variables, crossed multiplied variables—e.g., piecewise regression—or polynomial transformations) or by considering semi-parametric or non-parametric models.

Another criticism that can be made of the hedonic pricing model is related to the more general problem of omission of significant variables in the specification [33-35]. Since it is almost impossible to measure all the different amenities of the goods, there is a strong possibility that the omission of such a measurement may introduce bias into the estimated coefficients. This is even more important when the main variable of interest is closely correlated with the omitted variables. The variable omission problem is tightly bound up with the problem of spatial autocorrelation. The omission of a spatially structured independent variable generally results in a spatial pattern detected among the residuals of the models. According to [36] imposing particular relations among the variables of the model can also generate spatial autocorrelation.

One of the possible solutions to solve the problem of the omission of spatial variables from the specification has been to adopt spatial autoregressive specifications developed in spatial econometrics. Without loss of generality, spatial econometric models rely on the addition of a: (i) spatial spillover effect (SAR model—Equation (2)); (ii) a spatial externalities effect (SLX model—Equation (3)); or (iii) a latent spatial effect (SEM model-Equation (4)).

$$
\begin{gathered}
\mathbf{y}=\varrho \mathbf{W} \mathbf{y}+\alpha \mathbf{\imath}+\mathbf{X} \boldsymbol{\beta}+\varepsilon \\
\mathbf{y}=\alpha \mathbf{\imath}+\mathbf{X} \boldsymbol{\beta}+\mathbf{W} \mathbf{X} \boldsymbol{\theta}+\varepsilon \\
\mathbf{y}=\alpha \mathbf{\imath}+\mathbf{X} \boldsymbol{\beta}+\mathbf{u} \\
\mathbf{u}=\lambda \mathbf{W} \mathbf{u}+\varepsilon
\end{gathered}
$$

where $\mathbf{W}$ is an (exogenous) spatial weights matrix of dimension $(\mathrm{N} \times \mathrm{N})$, expressing the possible spatial relations (or connections) among the observations, the parameters $\varrho$ and $\lambda$, and the vector of parameters $\theta$ of dimension $(P \times 1)$, that allows us to capture the spatial effects (with $P \leq K)$, while $\varepsilon$ is the vector of error terms, which is assumed to be homoskedastic and independent. The autoregressive parameter $\varrho$ capture the global spatial effect, while the vector of parameters $\theta$ capture the local spatial effect $[16,17,37]$.

Recently, many authors have suggested adopting a general spatial Durbin model as the reference model (SDM model—Equation (5)) because it generalizes the SAR and SLX models, while being a special case of the SEM model $[37,38]$ (A mathematical manipulation can be made to write the SEM model as $\mathbf{y}=\lambda \mathbf{W} \mathbf{y}+\alpha \mathbf{\imath}+\mathbf{X} \boldsymbol{\beta}+\mathbf{W X}(\lambda \boldsymbol{\beta})+\varepsilon)$.

$$
\mathbf{y}=\varrho \mathbf{W} \mathbf{y}+\alpha \mathbf{t}+\mathbf{X} \boldsymbol{\beta}+\mathbf{W} \mathbf{X} \boldsymbol{\theta}+\varepsilon
$$

One advantage of the spatial econometric specification, except for the SEM model, is that it allows us to decompose the marginal effect into separate components $[16,28]$. For the SLX model, the marginal effect is direct, but no longer equal to the coefficient $\beta_{\mathrm{k}}$ (Equation (6)). 


$$
\partial \mathbf{y} / \partial \mathbf{x}_{\mathrm{k}}=\left(\mathbf{I} \beta_{\mathrm{k}}+\mathbf{W} \theta_{\mathrm{k}}\right)
$$

where $\mathbf{I}$ is the identity matrix of dimension $(\mathrm{N} \times \mathrm{N})$. With the weights matrix $\mathbf{W}$ row-standardized, the interpretation can be simplified to include the local spatial (externalities) effect $\left(\theta_{\mathrm{k}}\right)$. In such a case, the marginal effect is decomposed into a direct effect $\left(\beta_{\mathrm{k}}\right)$ and the total effect $\left(\beta_{\mathrm{k}}+\theta_{\mathrm{k}}\right)$.

For SAR and SDM models, $[16,17]$ show that the marginal effect is given by the partial derivative of the $\mathbf{y}$ reduced form equation with respect to a change in variable $\mathbf{x}_{\mathrm{k}}$ (Equation (7)). In the SAR specification $\theta_{\mathrm{k}}=0$ and the second term on the right-hand side can be simplified.

$$
\partial \mathbf{y} / \partial \mathbf{x}_{\mathrm{k}}=(\mathbf{I}-\varrho \mathbf{W})^{-1}\left(\mathbf{I} \beta_{\mathrm{k}}+\mathbf{W} \theta_{\mathrm{k}}\right)
$$

where $(\mathbf{I}-\varrho \mathbf{W})^{-1}$ is a spatial multiplier that can be expressed as the sum of powers of the weights matrix $\mathbf{W}$ (Equation (8)-[16,39]) (According to the infinite series properties).

$$
(\mathbf{I}-\varrho \mathbf{W})^{-1}=\mathbf{I}+\varrho \mathbf{W}+\left(\varrho^{2} \mathbf{W}^{2}+\varrho^{3} \mathbf{W}^{3}+\varrho^{4} \mathbf{W}^{4}+\ldots\right)=\mathbf{S}(\mathbf{W})
$$

Different interpretations have been made of the expression in Equations (7) and (8) in the SAR model context. On the one hand, some propose to decompose marginal effect into: (i) a direct effect, as measured by the $\mathbf{I} \beta_{k}$ (or by $\left[\mathbf{I} \beta_{k}+\mathbf{W} \theta_{k}\right]$ for the SDM); (ii) an induced effect, as measured by $\varrho \mathbf{W} \beta_{\mathrm{k}}$ (or $\left.\left.\varrho \mathbf{W}\left[\mathbf{I} \beta_{\mathrm{k}}+\mathbf{W} \theta_{\mathrm{k}}\right]\right)\right) ;\left(\right.$ Or by $\varrho \beta_{\mathrm{k}}$ or $\varrho\left(\beta_{\mathrm{k}}+\theta_{\mathrm{k}}\right)$ when the weights matrix $\mathbf{W}$ is row-standardized) and (iii) a spillover effect, as measured by the rest of the terms appearing in parentheses on the right-hand side of Equation (8) multiplied by $\mathbf{I} \beta_{\mathrm{k}}$ (or $\left(\mathbf{I} \beta_{\mathrm{k}}+\mathbf{W} \theta_{\mathrm{k}}\right)$ ) [39]. On the other hand, others argue that the marginal effect should be decompose into: (i) the direct effect, as measured by the mean elements appearing on the diagonal of the matrix $\mathbf{S}(\mathbf{W}) \mathbf{I} \beta_{\mathrm{k}}$ for the SAR model or $\mathbf{S}(\mathbf{W})\left(\mathbf{I} \beta_{\mathrm{k}}+\mathbf{W} \theta_{\mathrm{k}}\right)$ for the SDM specification; (ii) the indirect effect, as measured by the mean of the elements appearing on the off-diagonal; and (iii) the sum of both effect to yield the total marginal effect [5].

It is also demonstrated that when weights matrices matrixes are row-standardized, the spatial multiplier can be expressed as $(1-\varrho)^{-1}$ (see [16,39-42]). In such a case, the total marginal effect can be expressed as $\beta_{\mathrm{k}} /(1-\varrho)$ for the SAR model and $\left(\beta_{\mathrm{k}}+\theta_{\mathrm{k}}\right) /(1-\varrho)$ in the SDM model [43]. Using such a simplification to express the total marginal effect, [28] have suggested that $\beta_{k}$, for the SAR model, or $\left(\beta_{k}+\theta_{k}\right)$ for the SDM model can be interpreted as direct effects. The difference between the total marginal effect and the direct marginal effect enables us to ascertain the indirect marginal effect. This interpretation greatly simplifies the calculation, while returning an interpretation akin to the one usually made within a multiple regression framework. However, it does not allow us to directly retrieve the significance of such marginal effects, except for the direct marginal effects.

Marginal effect in the hedonic pricing model should be interpreted with caution when applied to real-estate data ([40]). Spatial multiplier only applies when the change in the independent variables, $\mathbf{x}_{\mathrm{k}}$, results from a technological change and not from a pecuniary change. Thus, there is a challenge to distinguish between technological and pecuniary changes. However, this challenge can be partly solved when working with cross-sectional data that also include a time factor, such as real-estate transactions.

This section may be divided by subheadings. It should provide a concise and precise description of the experimental results, their interpretation as well as the experimental conclusions that can be drawn.

\subsection{Spatial Data Pooled over Time and Weights Matrices}

The spatial structure of transactions raises no doubt (they certainly occur somewhere), but the transactions also occur at given times. The pure cross-sectional structure of spatial data imply that the observations $(i=1,2, \ldots, \mathrm{N})$ are collected in the same time window, and that the total sample size is equal to $\mathrm{N}$. In spatial panel data, the individual observations $(i=1,2, \ldots, N)$ are observed in each time period $(t=1,2, \ldots, \mathrm{T})$ and the total sample size for a fully balanced panel is equal to NT. These two cases clearly fail to account for the particularity of the transaction data. For spatial data pooled 
over time, such as transaction data, the total number of observations collected in each time period is different $\left(i_{\mathrm{t}}=1,2, \ldots, \mathrm{N}_{\mathrm{t}}\right)$, while individual observations are rarely repeated over time. In such a case, the total sample size is equal to $\mathrm{N}_{\mathrm{T}}\left(\mathrm{N}_{\mathrm{T}}=\Sigma_{\mathrm{t}} \mathrm{N}_{\mathrm{t}}\right.$ for $\left.t=1,2, \ldots, \tau\right)$. The visual reading of such data can be seen as a collection of spatial layers of information pooled over time when data are aggregated into discrete time periods [25]. Consequently, the dimensions of the matrices and vectors depend on the nature of the data under consideration, while the validity of the estimation of the parameters relies on the observance of the usual assumptions made about the error terms.

Moreover, the structure of the weights matrix needs to account for the temporal dimension of the spatial data. To isolate for spatial multidirectional effects, a temporal weights matrix, $\mathbf{T}$, with a general element $t_{i j}$ taking a value of 1 if observations $i$ and $j$ are collected in the same time period (or interval) and 0 otherwise is built $[23,43,44]$. This temporal weights matrix is then after multiplied, element-by-element, with a general spatial weights matrix, $\mathbf{W}$, to obtain a general weights matrix that enables us to isolate multidirectional spatial effect: $\mathbf{S}=\mathbf{W} \odot \mathbf{T}$, where $\odot$ is a Hadamard product. The individual elements of the spatial weights matrix are defined as usual, i.e., as a function of the distance separating two observations $i$ and $j$ such that $\mathrm{w}_{\mathrm{ij}}=\mathrm{f}\left(\mathrm{d}_{\mathrm{ij}}\right)$, where $\mathrm{f}(\cdot)$ could be any decreasing function, assigning a higher value to closer observations and a lower value to more remote observations.

Another spatial effect is also possible for such a database. A spatial unidirectional effect, i.e., how previous observations were spatially located can influence actual observations, is possible. To account for such a possibility, it is possible to generate a second temporal weights matrix. By noting $\underline{\mathbf{T}}$ a general weights matrix indicating the temporal distance among observations $i$ and $j$ if observation $\mathrm{j}$ has been collected before $\mathrm{i}$, then a general weights matrix $\underline{\mathbf{W}}=\mathbf{W} \odot \underline{\mathbf{T}}$, can be used to isolate a spatial unidirectional effect $[24,28]$ (As previously argued by $[43,44]$, the form of both temporal weights matrices, $\mathbf{T}$ and $\underline{\mathbf{T}}$, can be simplified if the observations are chronologically ordered beforehand. In such a case, the temporal weights matrix takes on a structure divided into three separate parts: (i) the upper-triangular part is defined by elements all equal to zero (0), indicating that future observations cannot exert any influence on present or past observations; (ii) a block-diagonal structure that isolates observations occurring in the same time period, or in the same time window; and (iii) a lower-triangular part that expresses the possible relations between previous observations and current observations).

Using this notation, it is possible to build a new variable, $\underline{\mathbf{W}} \mathbf{y}_{\mathrm{t}-1}$, that, when $\underline{\mathbf{W}}$ is row-standardized, expresses the mean value of $\mathbf{y}$ for observations collected previously within a spatial delimitation. One interesting feature of this new variable is that it can be seen as strictly exogenous (Since the observations are not the same in each time period, it is necessary to use a different notation than the spatial panel case where the observations are repeated in each time period and the same weights matrix is used).Thus, the standard linear regression model can incorporate the variable $\underline{\mathbf{W}_{\mathbf{t}-1}}$ in the specification and the model can still be estimated using ordinary least squares (OLS) or generalized least squares (GLS) $[17,34]$. By denoting $\psi$ the additional coefficient related to the variable $\underline{\mathbf{W}}_{\mathbf{t}-1}$, and by using the weights matrix $\mathbf{S}$ based on the Hadamard product to isolate spatial multidirectional effects, one obtains a more complex set of (spatio-temporal) models (Equations (9)-(12), see [23]).

$$
\begin{gathered}
\mathbf{y}_{\mathrm{t}}=\varrho \mathbf{S} \mathbf{y}_{\mathrm{t}}+\psi \underline{\mathbf{W}} \mathbf{y}_{\mathrm{t}-1}+\alpha \mathbf{t}+\mathbf{X}_{\mathrm{t}} \boldsymbol{\beta}+\varepsilon_{\mathrm{t}} \\
\mathbf{y}_{\mathrm{t}}=\alpha \mathbf{t}+\psi \underline{\mathbf{W}} \mathbf{y}_{\mathrm{t}-1}+\mathbf{X}_{\mathrm{t}} \boldsymbol{\beta}+\mathbf{S} \mathbf{X}_{\mathrm{t}} \boldsymbol{\theta}+\varepsilon_{\mathrm{t}} \\
\mathbf{y}_{\mathrm{t}}=\alpha \mathbf{\imath}+\psi \underline{\mathbf{W}} \mathbf{y}_{\mathrm{t}-1}+\mathbf{X}_{\mathrm{t}} \boldsymbol{\beta}+\mathbf{u}_{\mathrm{t}} \\
\mathbf{u}_{\mathrm{t}}=\lambda \mathbf{S} \mathbf{u}_{\mathrm{t}}+\varepsilon_{\mathrm{t}} \\
\mathbf{y}_{\mathrm{t}}=\varrho \mathbf{S} \mathbf{y}_{\mathrm{t}}+\psi \underline{\mathbf{W}} \mathbf{y}_{\mathrm{t}-1}+\alpha \mathbf{t}+\mathbf{X}_{\mathrm{t}} \boldsymbol{\beta}+\mathbf{S} \mathbf{X}_{\mathrm{t}} \boldsymbol{\theta}+\varepsilon_{\mathrm{t}}
\end{gathered}
$$

where the marginal effects previously presented (Equation (7)) still hold since the change of $x_{k}$ in time $t$ does not influence the variable $\mathrm{y}_{\mathrm{t}-1}$ and $\underline{\mathbf{W}}_{\mathrm{t}-1}$ is exogenous from the time period $t$ (In such a case, the data generating process can be expressed as $\mathbf{y}_{\mathrm{t}}=(\mathbf{I}-\varrho \mathbf{S})^{-1}\left[\psi \underline{\mathbf{W}} \mathbf{y}_{\mathrm{t}-1}+\alpha \mathbf{t}+\mathbf{X}_{\mathrm{t}} \boldsymbol{\beta}+\mathbf{S} \mathbf{X}_{\mathbf{t}} \theta\right]$ and the partial derivative of the function $\mathbf{y}_{\mathrm{t}}$ with respect to $\mathbf{x}_{\mathrm{kt}}$ become $\left.\partial \mathbf{y}_{\mathrm{t}} / \partial \mathbf{x}_{\mathrm{kt}}=(\mathbf{I}-\varrho \mathbf{S})^{-1}\left(\mathbf{I} \beta_{\mathrm{k}}+\mathbf{S} \theta_{\mathrm{k}}\right)\right)$. 
However, an additional effect appears: a dynamic temporal effect, as measured by the coefficient $\psi$. Thus, considering the SDM specification (Equation (9)), the total marginal effect can be extended to calculate both the short-run (Equation (13)) and the long-run (Equation (14)) total marginal effects.

$$
\begin{gathered}
\partial \mathbf{y}_{\mathrm{t}+1} / \partial \mathbf{x}_{\mathrm{kt}}=\psi \times(\mathbf{I}-\varrho \mathbf{S})^{-1}\left(\mathbf{I} \beta_{\mathrm{k}}+\mathbf{S} \theta_{\mathrm{k}}\right) \\
\partial \mathbf{y}_{\mathrm{t}+\mathrm{s}} / \partial \mathbf{x}_{\mathrm{kt}}=(1-\psi)^{-1} \times(\mathbf{I}-\varrho \mathbf{S})^{-1}\left(\mathbf{I} \beta_{\mathrm{k}}+\mathbf{S} \theta_{\mathrm{k}}\right)
\end{gathered}
$$

Thus, it is possible to develop suitable models to account for spatial multidirectional and spatial unidirectional spatial relations in HP models. However, this approach does not necessarily ensure that the omitted variables problem is under control in HP models.

\section{Difference-in-Differences (DID) Estimator}

\subsection{Repeated-Sales (RS) Approach, or DID Estimator}

Hedonic pricing models have been adapted for multiple sales [45-47]. The repeated-sales (RS) approach is mainly used to generate price indexes, putting particular emphasis on the temporal dimension [48,49]. The RS (or DID) approach relies on two hedonic price equations: (i) one occurring at the time of the first sale (s-Equation (15)); and (ii) one occurring at the time of the second sale (resale) (r-Equation (16)).

$$
\begin{aligned}
& \mathbf{y}_{\mathrm{s}}=\alpha_{\mathrm{s}} \mathfrak{\imath}+\mathbf{X}_{\mathrm{s}} \beta+\mathbf{u}_{\mathrm{s}} \\
& \mathbf{y}_{\mathrm{r}}=\alpha_{\mathrm{r}} \mathfrak{\imath}+\mathbf{X}_{\mathrm{r}} \beta+\mathbf{u}_{\mathrm{r}}
\end{aligned}
$$

The difference between the price equation for the same goods, $\mathrm{i}$, resold at time $\mathrm{r}$ and sold at time $\mathrm{s}$ (Equation (17)), gives the repeated-sales estimator.

$$
\begin{gathered}
\left(\mathbf{y}_{\mathrm{r}}-\mathbf{y}_{\mathrm{s}}\right)=\left(\alpha_{\mathrm{r}}-\alpha_{\mathrm{s}}\right) \mathfrak{\imath}+\left(\mathbf{X}_{\mathrm{r}}-\mathbf{X}_{\mathrm{s}}\right) \boldsymbol{\beta}+\left(\mathbf{u}_{\mathrm{r}}-\mathbf{u}_{\mathrm{s}}\right) \\
\Delta \mathbf{y}_{\mathrm{t}}=\left(\alpha_{\mathrm{r}}-\alpha_{\mathrm{s}}\right) \mathfrak{\imath}+\Delta \mathbf{X}_{\mathrm{t}} \boldsymbol{\beta}+\varepsilon_{\mathrm{t}}
\end{gathered}
$$

The value of this model has mainly been to focus on the construction of the price index using the estimated coefficients $\alpha_{t}$. In such a case, the difference in the amenities of the goods $\left(\mathbf{X}_{\mathrm{r}}-\mathbf{X}_{\mathrm{s}}\right)$ is assumed to be zero, while the exponential of the coefficients $\alpha_{t}$ allows us to ascertain a global price index, with the first time period as the reference (price index $=1$ ).

The RS/DID approach has the advantage of eliminating the (constant) omitted variables from the HP model, and procuring a useful estimator (DID) allowing us to measure the effect of changes in $\mathbf{X}$ over time on price (or price growth) (This approach can also be extended to the case where no particular amenities change over time, but where the implicit prices of the amenities are assumed to evolve over time by denoting the implicit price by $\beta_{t}$ instead of $\beta$ in Equations (13) and (14)). This approach is used to measure the impact of changes in environmental (and exogenous) amenities on price or price growth $[29,30]$. Such an approach allows us to adequately control for most criticisms levelled at the hedonic pricing model.

Of course, one of the possible drawbacks of such an approach may be related to the selectivity problem. In this case, the multiple transactions may have characteristics that make them more likely to be sold and resold within a given time period. This problem can be formally tested using a logit or probit model to see whether being sold multiple times can be explained by their own characteristics. If so, a simple correction method, inspired by the Heckman transformation $[27,50,51]$ can be applied to control for this possible selectivity bias. If not, then the multiple transactions occurring have the same characteristics as the other transactions. However, in both cases, the total number of observations available to estimate the model is slightly reduced. To distinguish between the hedonic pricing model and the repeated-sales approach, the total number of observations is noted $n_{T}$ instead of $N_{T}$, where $N_{T} \gg n_{T}$ and where the total number of observations per period is given by $n_{t}$. 


\subsection{DID, SDID, STDID and Marginal Effects}

The DID approach appears to be one of the best ways to isolate the effect related to a (exogenous) change in the independent variable on a variable of interest [52]. Applied to real estate, DID has been proved to be a valuable way to evaluate the impact of environmental or landscaping policies. However, as mentioned by [53], this estimator neglects the possible spatial dimension of the price determination process. According to the spatial and temporal dimension of the price determination process, a spatial Durbin model (SDM) can express the sale price of a complex good, $\mathbf{y}_{\mathbf{t}}$, as a function of its own characteristics, $\mathbf{X}_{\mathbf{t}}$, but also as a function of the other sale prices occurring in the same time period around the good $i, \mathbf{S y}_{\mathbf{t}}$, and as a function of the characteristics of the goods sold within the same time period, $\mathbf{S} \mathbf{X}_{\mathbf{t}}$ (Equation (18)).

$$
\mathbf{y}_{\mathrm{t}}=\varrho \mathbf{S}_{\mathrm{t}}+\alpha_{\mathrm{t}} \mathbf{\imath}+\mathbf{X}_{\mathrm{t}} \boldsymbol{\beta}+\mathbf{S} \mathbf{X}_{\mathrm{t}} \boldsymbol{\theta}+\mathbf{u}_{\mathrm{t}}
$$

where $\mathbf{S}$ is a row-standardized weights matrix expressing the spatial relations for observations recorded in the same time period.

The spatial difference-in-differences (SDID) estimator can be written as a first difference equation between the price equation at the time of a resale and the first sale (Equation (19)).

$$
\Delta \mathbf{y}_{\mathrm{t}}=\left(\alpha_{\mathrm{r}}-\alpha_{\mathrm{s}}\right) \mathfrak{t}+\varrho \mathbf{S} \Delta \mathbf{y}_{\mathrm{t}}+\Delta \mathbf{X}_{\mathrm{t}} \boldsymbol{\beta}+\mathbf{S} \Delta \mathbf{X}_{\mathrm{t}} \boldsymbol{\theta}+\varepsilon_{\mathrm{t}}
$$

In such a case, the marginal effect of an exogenous change in amenities, relating mainly to a change in landscape policies or other public policies influencing the extrinsic amenities of a given good, takes a more complex expression introducing the spatial multiplier (Equation (20)).

$$
\partial \Delta \mathbf{y}_{\mathrm{t}} / \partial \Delta \mathbf{x}_{\mathrm{kt}}=\left(\beta_{\mathrm{k}}+\theta_{\mathrm{k}}\right) /(1-\varrho)
$$

This general framework can be used to account for both effects: spatial externalities and spatial spillover effects. It can also be used to decompose the marginal effect to account for such an effect in the calculation, much as [41] do for the SDID estimator.

In the literature, SDID estimators have been proposed, but most of them have focused on the introduction of spatial lagged variables of the independent variables in spatial panel specifications [54,55] — see also [56], while those models introducing a spatial lag of the dependent variable do not account for such an effect in calculating the marginal effect [43] (A recent study by [57] proposed an approach based on Geographically Weighted Regression (GWR)).

The HP model can also be extended to include the spatial unidirectional effect [31]. In such a case, the spatial and temporal dimension of the price determination process, a spatio-temporal Durbin model (STDM) introduces an additional variable: the sale price recorded in the previous time period,

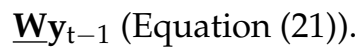

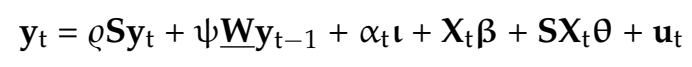

where $\underline{\mathbf{W}}$ is a row-standardized weights matrix isolating the spatial unidirectional relations, from observations collected from the previous time period.

As before, the spatio-temporal difference-in-differences (STDID) estimator can be written as a first difference equation between the price equation at the time of a resale and the first sale (Equation (22)).

$$
\Delta \mathbf{y}_{\mathrm{t}}=\left(\alpha_{\mathrm{r}}-\alpha_{\mathrm{s}}\right) \mathfrak{\imath}+\varrho \mathbf{S} \Delta \mathbf{y}_{\mathrm{t}}+\psi \underline{\mathbf{W}} \Delta \mathbf{y}_{\mathrm{t}-1}+\Delta \mathbf{X}_{\mathrm{t}} \boldsymbol{\beta}+\mathbf{S} \Delta \mathbf{X}_{\mathrm{t}} \boldsymbol{\theta}+\varepsilon_{\mathrm{t}}
$$

The STDID estimator allows us to retrieve the total marginal effect for a change in a given time period (Equation (20)), but also to calculate a spatial dynamic propagation effect. This effect can be decomposed into a short-term effect (Equation (23)) and a long-term effect (Equation (24)).

$$
\partial \Delta \mathbf{y}_{\mathrm{t}+1} / \partial \Delta \mathbf{x}_{\mathrm{kt}}=\psi\left(\beta_{\mathrm{k}}+\theta_{\mathrm{k}}\right) /(1-\varrho)
$$




$$
\partial \Delta \mathbf{y}_{\mathrm{t}+\infty} / \partial \Delta \mathbf{x}_{\mathrm{kt}}=\left(\beta_{\mathrm{k}}+\theta_{\mathrm{k}}\right) /[(1-\varrho)(1-\psi)]
$$

For a variation in the value of an independent variable for one (of few) observations, then, we can say that the value of the dependent variable will change $\left(\Delta \mathrm{x}_{\mathrm{ikt}} \rightarrow \Delta \mathrm{y}_{\mathrm{it}}\right)$ (Figure 1$)$. This is denoted by the direct (or first-round) effect. Thus, the first observation to record a change in the value of $y_{\text {it }}$ is the observation that first records an exogenous change in $x_{\mathrm{kt}}$. The variation in the value of $\mathrm{y}_{\mathrm{it}}$ will necessarily imply changes in values of the dependent variables for the other observations spatially close to the observations that have recorded a change in $\mathrm{x}$, and so on $\left(\Delta \mathrm{y}_{\mathrm{it}} \rightarrow \mathbf{S} \Delta \mathrm{y}_{\mathrm{it}} \rightarrow \Delta \mathrm{y}_{\mathrm{jt}}\right)$. Thus, the second wave of change implies the indirect effects. The change in the values of $y_{i t}$, and by extension of $\mathbf{S} \Delta \mathrm{y}_{\mathrm{it}}$, will necessarily impact the values of $\mathrm{y}_{\mathrm{it}+1}$, and $\mathbf{S} \Delta \mathrm{y}_{\mathrm{it}+1}$, and so on. These additional effects are spatially localized dynamic effects, generating short- and long-term direct effects.

In the end, the STDID estimator allows us to decompose the total effect of a change in the amenities on house prices into four (4) separate effects: (i) direct effect $\left(\beta_{\mathrm{k}}\right)$; (ii) direct spatial effect $\left(\beta_{\mathrm{k}}+\theta_{\mathrm{k}}\right)$ if the SDM or STDM specification is used); (iii) a total spatial effect $\left(\left(\beta_{\mathrm{k}}+\theta_{\mathrm{k}}\right) /(1-\varrho)\right)$; and (iv) a total short-term $\left(\psi \times\left[\left(\beta_{\mathrm{k}}+\theta_{\mathrm{k}}\right) /(1-\varrho)\right]\right)$ and total long-term marginal effect $\left(\left(\beta_{\mathrm{k}}+\theta_{\mathrm{k}}\right) /[(1-\varrho) \times(1-\psi)]\right)$ (Based on Equations (13) and (14)).
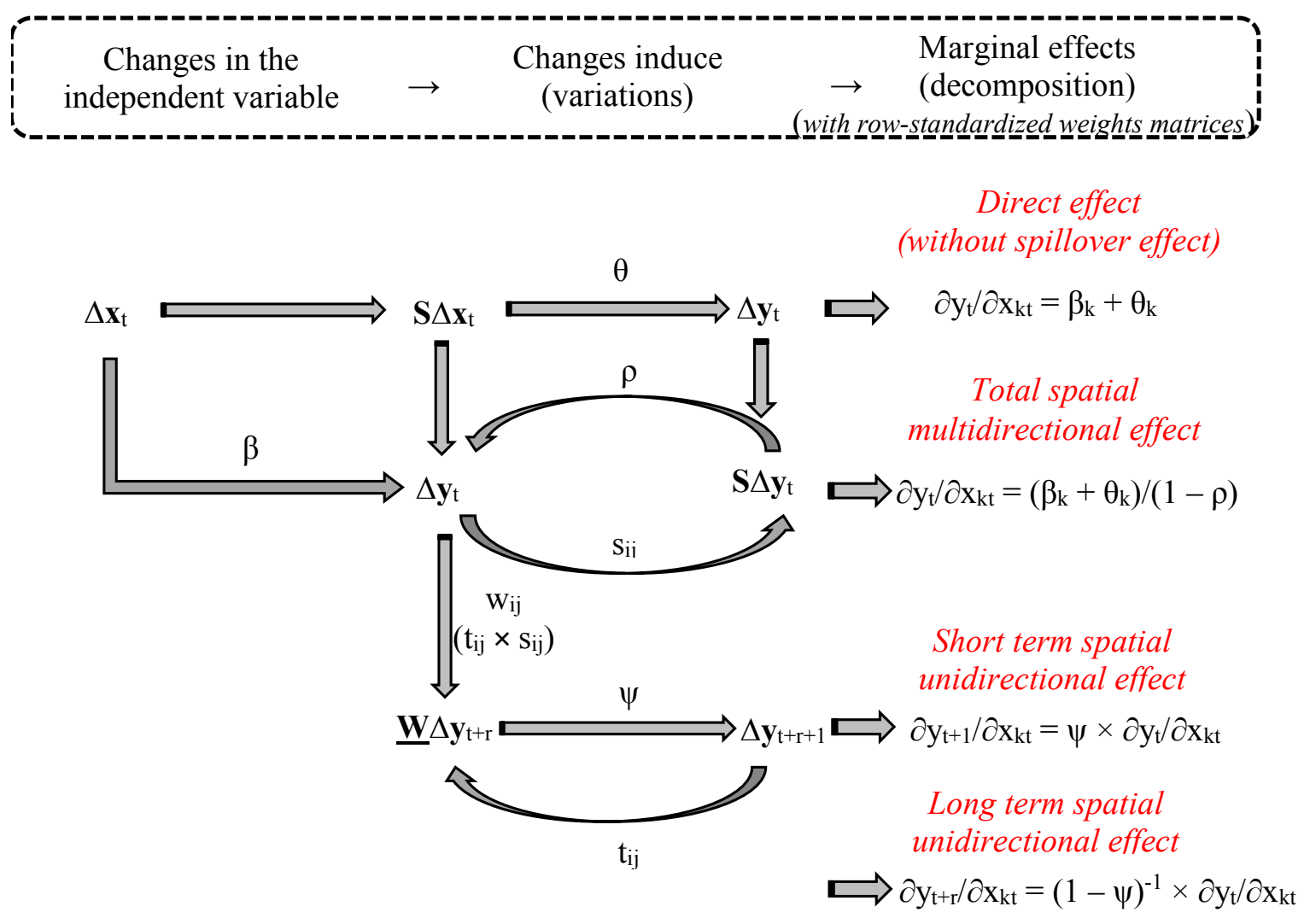

Figure 1. Schematic representation of the decomposition of the marginal effect according to the type of model selected.

We now turn to explore the impact of using such a decomposition of the marginal effect on empirical applications, or how should the information provided so far for analyzing a practical empirical case be used.

\section{Empirical Investigation}

The empirical investigation is based on a change in the mass transit system in metropolitan suburbs (The estimation has been performed with Stata software and the spreg command. More 
detail on the estimation procedure can be found in appendix of the book of [24]). The case study examines two separate commuter rail trains (CRT) in the Montreal (QC, Canada) metropolitan area. The first CRT serves the north shore part of the metropolitan area and was inaugurated in May 1997, when the first station opened in the municipality of Blainville and Sainte-Thérèse (the green line-Figure 2). Two more stations opened after that. The first was in Rosmère, a few months after the inauguration (1 January 1998), while the next stations only opened in January 2007 in St-Jérôme, the municipality located in the northern part of the metropolitan area. The impact of this new mass transit system has already been studied by [20]. The second CRT serves the eastern part of Montreal and has six stations. The service was officially introduced in 2000 when the first three stations opened, respectively Saint-Bruno (February 2000), and Saint-Lambert and McMasterville (May 2000). Two years after, the station of Mont-Saint-Hilaire was inaugurated (September 2002), while the last two stations opened in late 2003: Saint-Basile-le-Grand and Saint-Hubert (the purple line-Figure 2).

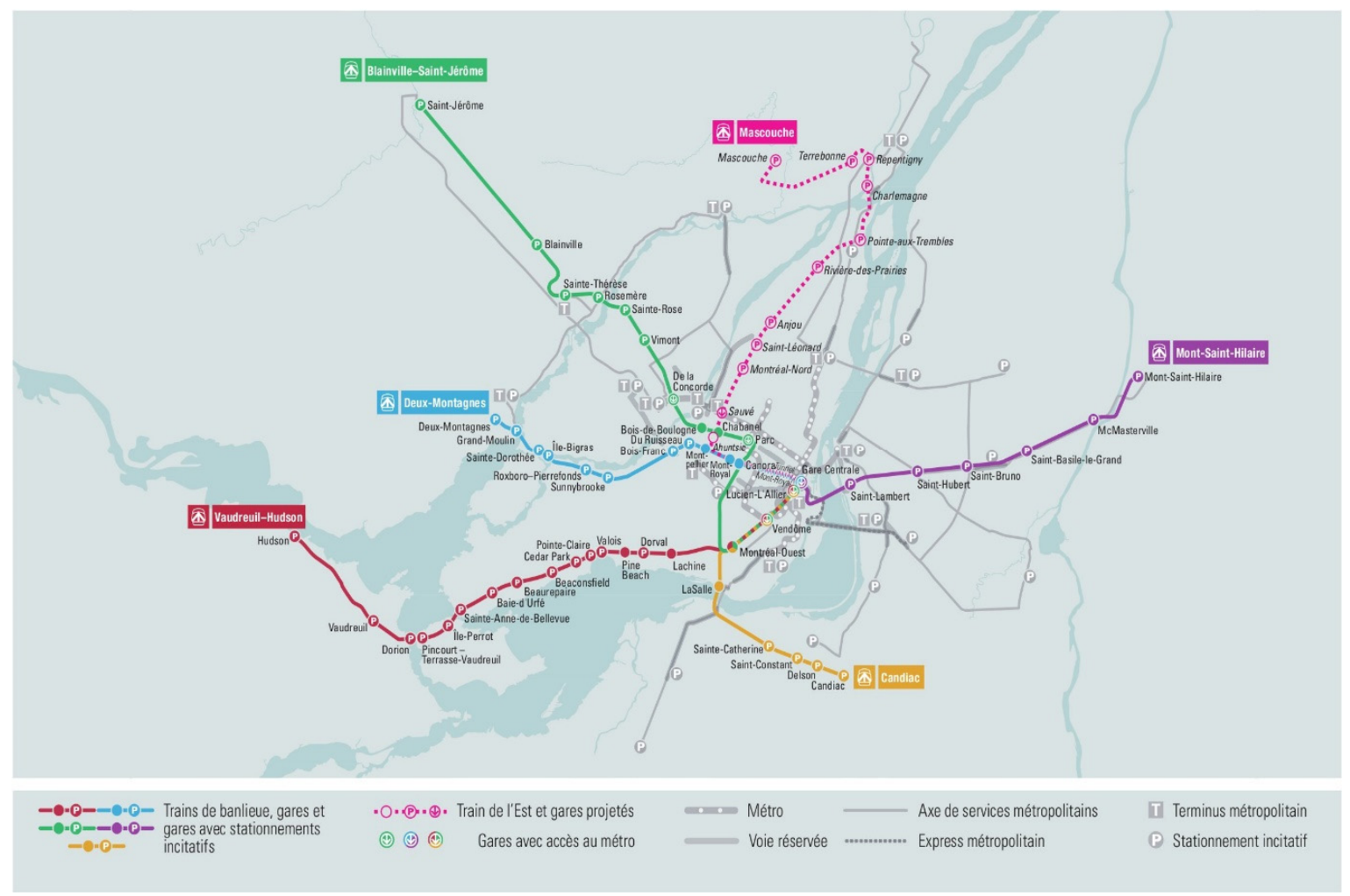

Figure 2. Map of the CRT system in the Montréal suburbs; Source: Agence Métropolitaine de Transport (AMT).

The transaction data on single-family properties, property characteristics, and prices come from the Greater Montreal Real Estate Board (GMREB) and have been cleaned and structured by the Altus Group (Quebec City, QC, Canada), an international appraisal firm operating throughout Canada. The data contain information on the detailed price deal (sale price, asking price, date of sale, particular context if any), the dwelling type, property age, building and land attributes (living area, number of bathrooms, finished basement, lot size, etc.) as well as information about any renovation to the house; outbuilding attributes (garage, swimming pool, shed, etc.) are also documented. Finally, data contain information about the extrinsic (location, neighbourhood, and environmental) characteristics of the property.

These two cases offer the possibility of studying the impact of the proximity of the houses to the stations on the price growth or property values since residential transactions are available between 1992 and 2009. The fact that some transactions were observed before and after the opening of the 
stations also allows us to use spatial difference-in-differences estimators [20] to investigate the impact, but also to calculate the marginal effect based on two separate spatial effects: the unidirectional spatial effect and the multidirectional spatial effect.

Since all accessibility times change for houses as a new station comes into operation and the effect is captured using a dummy variable, the STDM model (Equation (21)) does not appear suitable. This is because the variables in the matrix $\mathbf{S X}$ will necessarily be closely correlated to those in the matrix $\mathbf{X}$, introducing a collinearity problem. However, the price determination process can clearly depict a spatial component that can be controlled for using the STAR model (when $\boldsymbol{\theta}=\mathbf{0}$ in Equation (21)), which allows us to decompose the spatial effect into two separate spatial components.

The model largely simplifies the analysis and focuses on the impact of the changes on the house-price determination process. Here, the main characteristic that changes over time is the distance to the nearest station, which varies with the location of the house and the opening date of the stations. The models are estimated using the DID, SDID, and STDID estimators, allowing for a comparison of the effects depending on the specification used.

\subsection{Descriptive Statistics}

The pairs of transactions used in the analysis consider 6 years before the opening of the first station of the new mass transit system. In the case of the south-east CRT, the database includes transactions from 1995 until 2009 (Table 1), while in the case of the north CRT, transactions run from 1992 until 2009 (Table 2). In both cases, the number of transactions in the grey shaded part of the tables indicates houses that may experience a change in mass transit supply between sale and resale. These data are considered to form the treatment group, while transactions occurring both before and after the change in mass transit supply are considered to form the control group. The main idea of the DID, SDID, and STDID estimators is to use these treatment and control groups to infer the possible effect related to the opening of new CRT stations.

One advantage of the case study here is the fact that the new mass transit service operates on an existing railway system. The railway was mainly used to transport freight before the authorities decided to develop a CRT line on these existing lines. Consequently, there is no possible anticipation effect or any other cross-effect related to the implantation of the lines before the implementation of the new service. 
Table 1. Temporal distribution of the transactions along the south-east (purple) CRT line, 1995-2009.

\begin{tabular}{|c|c|c|c|c|c|c|c|c|c|c|c|c|c|c|c|}
\hline & Sale & & & & & & & & & & & & & & \\
\hline Resale & 1995 & 1996 & 1997 & 1998 & 1999 & 2000 & 2001 & 2002 & 2003 & 2004 & 2005 & 2006 & 2007 & 2008 & 2009 \\
\hline \multicolumn{16}{|l|}{1995} \\
\hline 1996 & 57 & 11 & & & & & & & & & & & & & \\
\hline 1997 & 117 & 68 & 13 & & & & & & & & & & & & \\
\hline 1998 & 126 & 141 & 60 & 15 & & & & & & & & & & & \\
\hline 1999 & 151 & 188 & 140 & 73 & 16 & & & & & & & & & & \\
\hline 2000 & 149 & 200 & 193 & 151 & 87 & 15 & & & & & & & & & \\
\hline 2001 & 160 & 212 & 226 & 198 & 204 & 143 & 22 & & & & & & & & \\
\hline 2002 & 136 & 204 & 188 & 220 & 252 & 209 & 161 & 28 & & & & & & & \\
\hline 2003 & 100 & 150 & 176 & 193 & 197 & 219 & 266 & 202 & 30 & & & & & & \\
\hline 2004 & 90 & 132 & 159 & 138 & 193 & 234 & 288 & 297 & 216 & 43 & & & & & \\
\hline 2005 & 82 & 123 & 139 & 147 & 178 & 190 & 257 & 298 & 257 & 217 & 42 & & & & \\
\hline 2006 & 64 & 118 & 120 & 104 & 131 & 137 & 216 & 308 & 268 & 286 & 159 & 29 & & & \\
\hline 2007 & 61 & 113 & 114 & 103 & 117 & 151 & 198 & 254 & 276 & 290 & 307 & 175 & 40 & & \\
\hline 2008 & 70 & 75 & 96 & 103 & 120 & 162 & 149 & 192 & 227 & 248 & 297 & 230 & 146 & 31 & \\
\hline 2009 & 58 & 67 & 87 & 93 & 95 & 139 & 175 & 206 & 194 & 235 & 246 & 257 & 229 & 148 & 19 \\
\hline
\end{tabular}


Table 2. Temporal distribution of the transactions along the north (green) CRT line, 1992-2009.

\begin{tabular}{|c|c|c|c|c|c|c|c|c|c|c|c|c|c|c|c|c|c|c|}
\hline & Sale & & & & & & & & & & & & & & & & & \\
\hline Resale & 1992 & 1993 & 1994 & 1995 & 1996 & 1997 & 1998 & 1999 & 2000 & 2001 & 2002 & 2003 & 2004 & 2005 & 2006 & 2007 & 2008 & 2009 \\
\hline 1992 & & & & & & & & & & & & & & & & & & \\
\hline 1993 & 5 & 0 & & & & & & & & & & & & & & & & \\
\hline 1994 & 21 & 34 & 7 & & & & & & & & & & & & & & & \\
\hline 1995 & 32 & 56 & 29 & 1 & & & & & & & & & & & & & & \\
\hline 1996 & 58 & 89 & 64 & 39 & 5 & & & & & & & & & & & & & \\
\hline 1997 & 47 & 94 & 93 & 78 & 46 & 8 & & & & & & & & & & & & \\
\hline 1998 & 39 & 81 & 104 & 93 & 90 & 59 & 7 & & & & & & & & & & & \\
\hline 1999 & 39 & 79 & 119 & 89 & 138 & 111 & 69 & 11 & & & & & & & & & & \\
\hline 2000 & 47 & 63 & 91 & 101 & 149 & 146 & 119 & 95 & 17 & & & & & & & & & \\
\hline 2001 & 38 & 84 & 102 & 93 & 141 & 173 & 171 & 209 & 109 & 17 & & & & & & & & \\
\hline 2002 & 31 & 87 & 112 & 105 & 147 & 181 & 197 & 235 & 212 & 199 & 32 & & & & & & & \\
\hline 2003 & 43 & 64 & 81 & 74 & 125 & 114 & 163 & 198 & 217 & 264 & 216 & 48 & & & & & & \\
\hline 2004 & 27 & 52 & 66 & 67 & 100 & 127 & 140 & 201 & 228 & 276 & 324 & 218 & 43 & & & & & \\
\hline 2005 & 16 & 40 & 56 & 68 & 95 & 98 & 143 & 138 & 183 & 269 & 318 & 309 & 258 & 30 & & & & \\
\hline 2006 & 18 & 42 & 50 & 56 & 74 & 86 & 75 & 125 & 128 & 189 & 242 & 313 & 319 & 209 & 23 & & & \\
\hline 2007 & 20 & 40 & 48 & 51 & 91 & 78 & 112 & 109 & 168 & 188 & 247 & 284 & 362 & 369 & 228 & 40 & & \\
\hline 2008 & 16 & 28 & 32 & 45 & 60 & 68 & 74 & 94 & 110 & 156 & 194 & 212 & 275 & 283 & 305 & 165 & 24 & \\
\hline 2009 & 10 & 29 & 39 & 52 & 54 & 68 & 71 & 104 & 87 & 157 & 171 & 201 & 263 & 305 & 310 & 269 & 134 & 25 \\
\hline
\end{tabular}


In both cases, the number of transactions (sale and resale) are comparable, with a larger number of first transactions (sale) occurring at the beginning of the database that progressively decreased over time, while having a small number of second transactions (resale) occurring at the beginning of the database, but where the number progressively increases as years go by (Figure 3). The total number of transactions is also quite comparable within the database, with a total of 18,320 pairs of transactions recorded for the south-east shore of the metropolitan area for the east CRT line, and with a total of 19,808 pairs of transactions for the north shore.

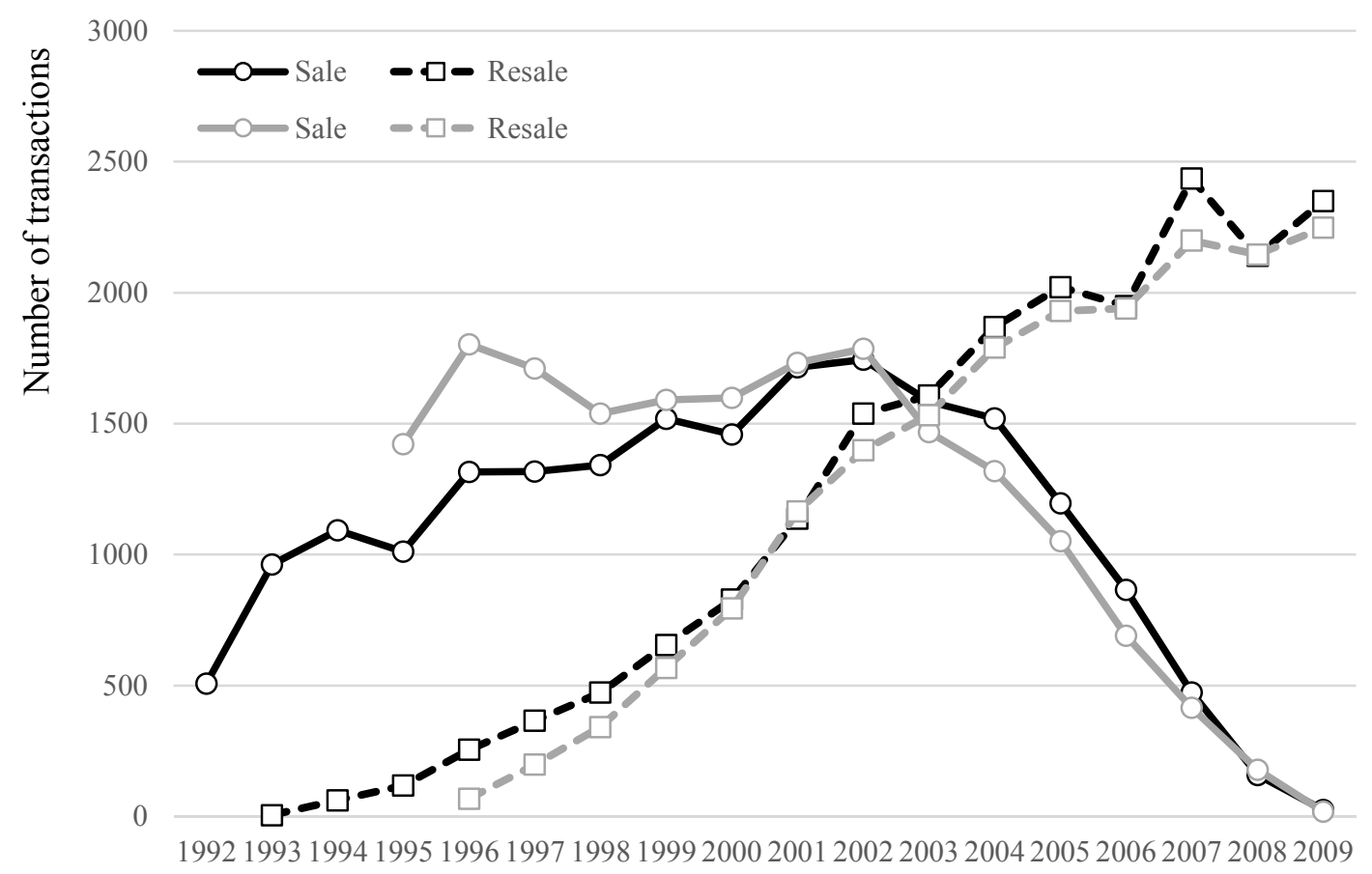

Year of transaction

Figure 3. Temporal distribution of sales and resales over time for both samples, 1992-2009; Legend: grey $\rightarrow$ south shore, black $\rightarrow$ north shore; solid line $\rightarrow$ sale, dashed line $\rightarrow$ resale.

The spatio-temporal distribution of sales reveals that the most important variation in time to access the nearest station is recorded for the south-east CRT line (Figure 4) (All distances where calculated based on operational road network and implemented within the Network Analyst extension of ArcGIS (ESRI) - see [29,31] for more detail). This is so because there was already a CRT station that served the north shore (Deux-Montagnes). Thus, the appearance of new stations reduced the mean time to access the nearest stations, but the gain was less important on the north shore. The fact that some time distance gains are negative for the north shore indicates that some houses were originally at a distance of between 10 and $12 \mathrm{~min}$ to the nearest station and that, after that the new CRT station opened, the distance to the nearest station fell to 2 or $4 \mathrm{~min}$. A total of 6837 houses experienced a decrease in the total time to the nearest station for the south-east CRT line, while this number was only 1877 for the north CRT line. This is also related to the fact that the last station on the north-shore opened in 2007.

Some transactions have also experienced a change in "on foot" accessibility to the nearest station. By differentiating the possible effect into three separate walkable zones, defined by a radius of influence of $500 \mathrm{~m}$, (The distance was selected to make sure that enough observations were available within these ranges to correctly estimate the possible effect) it appears once again that the place where more changes occurs is on the east CRT line (Table 3). In both cases, the number of houses experiencing a positive change in accessibility by being within $500 \mathrm{~m}$ of the station are rare: 12 cases for the south-east 
CRT line and 22 cases for the north CRT line. The change for houses located between 500 and $1500 \mathrm{~m}$ is higher, varying between 78 and 424 .

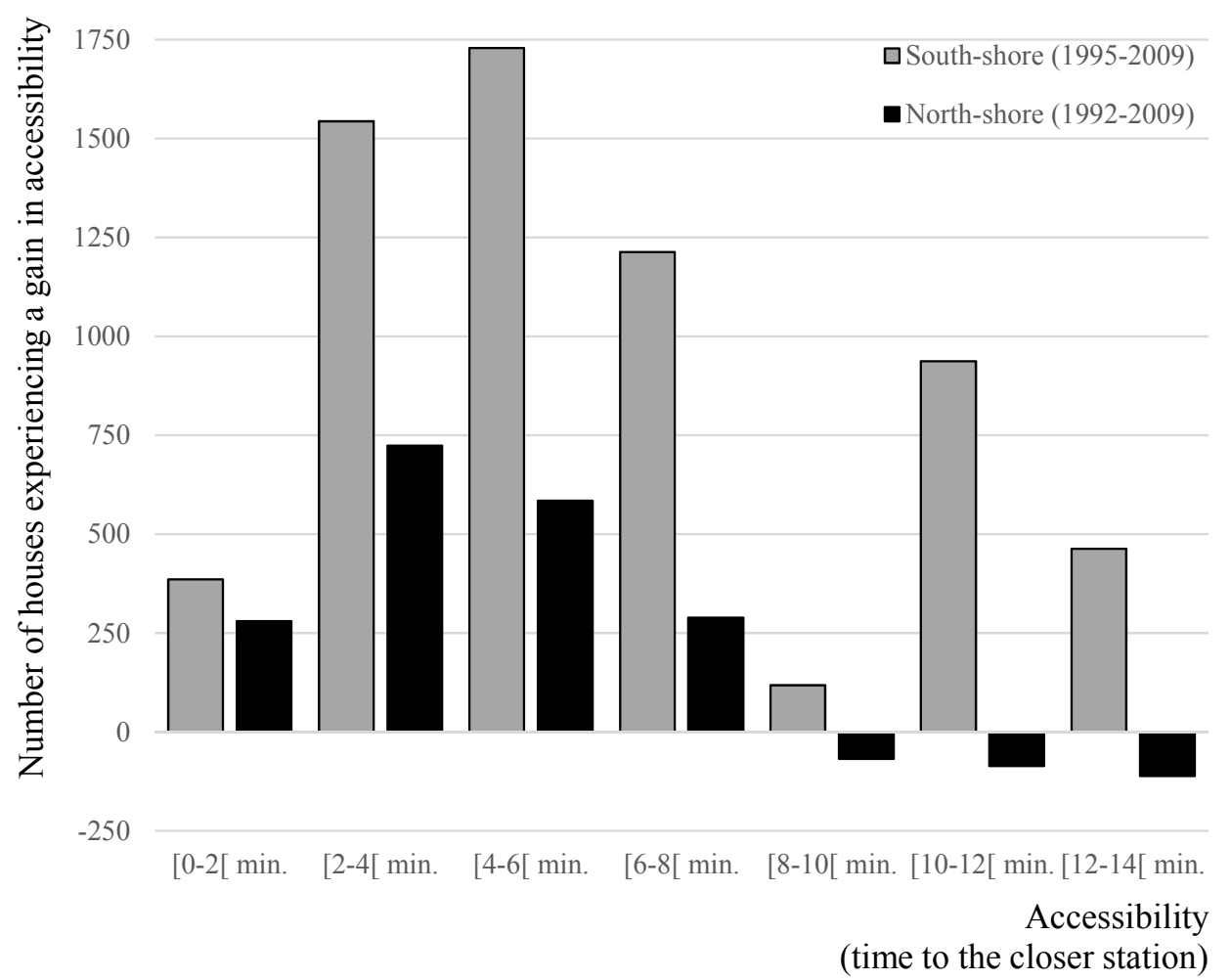

Figure 4. Number of housing experiencing a change in accessibility to the nearest CRT station. Legend: grey $\rightarrow$ south shore, black $\rightarrow$ north shore; solid line $\rightarrow$ sale, dashed line $\rightarrow$ resale. Notes: For the $x$-axis, the sign [ on the left signify that the value in included, while the sign [ on the right means that the value is not included.

Table 3. Number of houses experiencing improved "on foot" accessibility.

\begin{tabular}{ccc}
\hline$\Delta$ Walking Distance & South & North \\
\hline$(0-500) \mathrm{m}$ & 12 & 22 \\
$(50-1000) \mathrm{m}$ & 122 & 78 \\
$(1000-1500) \mathrm{m}$ & 424 & 198 \\
No improvement & 17,762 & 19,510 \\
Total & 18,320 & 19,808 \\
\hline
\end{tabular}

Before turning our attention to the estimation results, let us mention that the distribution of the dependent variables, the difference in the log sale (and resale) price shows an interesting pattern, that is not purely normally distributed but not too far from it (Figure 5). Since the dependent variable express the difference in the log sale prices, this variable can be seen as an approximation of price growth. The mean growth was $35.02 \%$ for south-east shore transactions versus $31.23 \%$ for north shore transactions. 


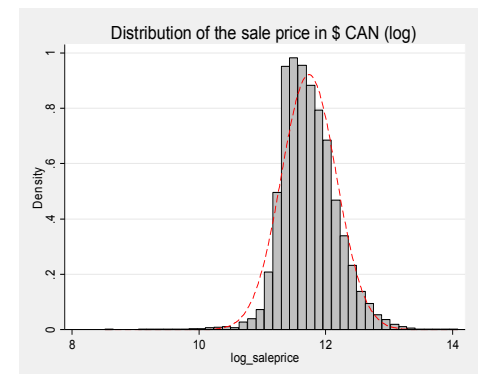

(a)

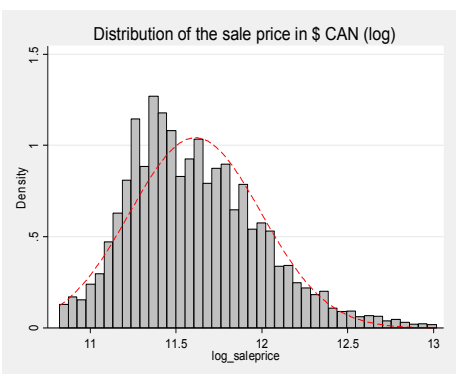

(d)

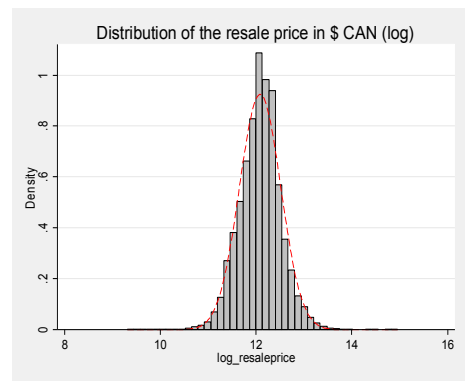

(b)

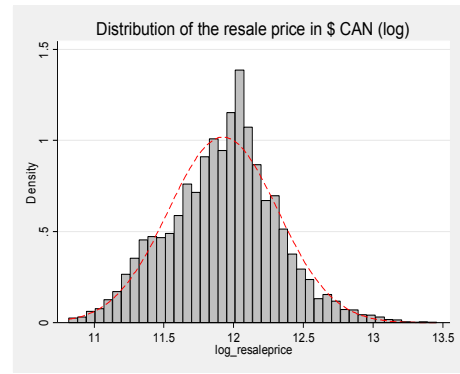

(e)

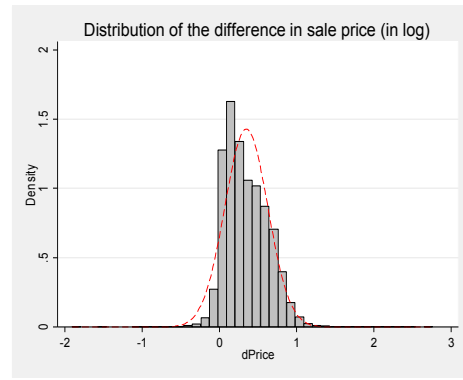

(c)

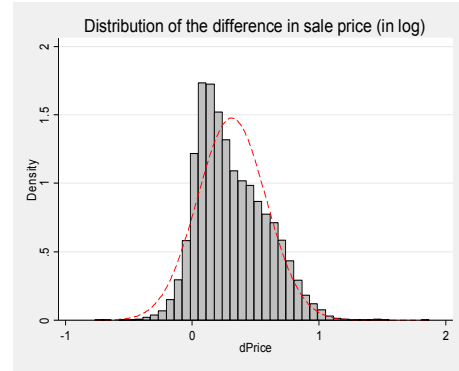

(f)

Figure 5. Distribution of the sale and resale price according to the logarithmic transformation among samples: (a) Distribution of (first) sale price for the south-east corridor; (b) Distribution of (second) resale price for the south-east corridor; (c) Difference between resale and sale price for the south-east corridor; (d) Distribution of (first) sale price for the north corridor; (e) Distribution of (second) resale price for the north corridor; (f) Difference between resale and sale price for the north corridor.

\subsection{Estimation Results}

For the exercise, the models were specified using a complex pattern of price appreciation incorporating an anisotropic representation of the shape of the effect on house price. Thus, the dummy variables indicating an improvement in accessibility to the nearest station are also multiplied by the distance of individual houses to the Montreal CBD (see [29]) (Define with reference to the location of the Place Ville-Marie, the highest skyscraper in downtown Montreal). This functional form allows the effect to be increasing or decreasing with the distance to the CBD and introduces an anisotropic location rent pattern.

\subsubsection{The South-East CRT Line}

The first estimation result is for the south-east CRT line. The comparison between the estimated coefficients obtained from the DID, the SDID, and the STDID reveals only minor differences (Table 4). On the overall performance, the pseudo- $R^{2}$ is higher in the STDID model, but the gain is marginal. The Akaike information criterion (AIC) and the Schwartz information criterion (BIC) both indicate the significant gain of considering the SDID and STDID estimator instead of the usual DID approach. This is also confirmed by comparing the log-likelihood statistics. A log-likelihood ratio (LR) test indicates that both specifications are statistically preferable to the DID model (LR $=142.62$ for the SDID and LR $=159.92$ for the STDID). This is also supported by the fact that the autoregressive coefficients are statistically significant, as proposed by the t-test. The comparison between the SDID and the STDID is less clear, but the LR test indicates that the STDID model is preferable ( $L R=17.20)$. Thus, statistically, the STDID model performs better globally.

Regarding the individual effect of the proximity of the station on house price, the significant effect appears to be spatially diffused within less than a 10-min drive from the nearest station, for the SDID and the STDID. This is also the case for the DID, but the effect appears to be significant for houses located within a 10 to 12 -min drive from the nearest station. The cross-effect with distance to 
the CBD is also significant for the 4 to 6 min-drive for the DID only. Thus, taking into account the spatial consideration of spillover effects influences the significance of some parameters. This suggests that the spatial dimension, if not explicitly taken into account in the model, contributes to some extent, to the omitted variable problem, generating bias on the estimated coefficients.

Table 4. Estimation results for the south-east CRT line (purple line).

\begin{tabular}{|c|c|c|c|c|c|c|}
\hline \multirow{2}{*}{$\begin{array}{c}\text { Models } \\
\text { Variables }\end{array}$} & \multicolumn{2}{|c|}{ DID Equation (17) } & \multicolumn{2}{|c|}{ SDID Equation (19) } & \multicolumn{2}{|c|}{ STDID Equation (22) } \\
\hline & Coeff. & Sign. & Coeff. & Sign. & Coeff. & Sign. \\
\hline \multicolumn{7}{|l|}{$\Delta$ Sale situation } \\
\hline Forclosure & -0.1468 & $* * *$ & -0.1473 & $* * *$ & -0.1474 & $* * *$ \\
\hline Without legal warranty & -0.0792 & $* * *$ & -0.0778 & $* * *$ & -0.0776 & $* * *$ \\
\hline Succession & -0.0898 & $* * *$ & -0.0824 & $* * *$ & -0.0816 & $* * *$ \\
\hline Transfer & -0.0178 & $* * *$ & -0.0189 & $* * *$ & -0.0190 & $* * *$ \\
\hline \multicolumn{7}{|l|}{$\Delta$ Walking distance } \\
\hline$(0-500) \mathrm{m}$ & 0.0573 & & 0.0570 & & 0.0578 & \\
\hline$(500-1000) \mathrm{m}$ & 0.0408 & * & 0.0379 & * & 0.0380 & * \\
\hline$(1000-1500) \mathrm{m}$ & 0.0080 & & 0.0076 & & 0.0075 & \\
\hline \multicolumn{7}{|l|}{$\Delta$ Driving distance } \\
\hline$(0-2) \mathrm{min}$. & 0.1743 & $* * *$ & 0.1773 & $* * *$ & 0.1774 & $* * *$ \\
\hline$(2-4) \mathrm{min}$. & 0.1199 & $* * *$ & 0.1179 & $* * *$ & 0.1177 & $* * *$ \\
\hline (4-6) $\min$. & 0.0528 & $* * *$ & 0.0517 & $* * *$ & 0.0519 & $* * *$ \\
\hline$(6-8) \mathrm{min}$. & -0.0148 & & -0.0149 & & -0.0145 & \\
\hline$(8-10) \mathrm{min}$. & 0.0427 & $* * *$ & 0.0410 & $* *$ & 0.0408 & $* *$ \\
\hline$(10-12) \mathrm{min}$. & 0.0378 & $* *$ & 0.0363 & & 0.0361 & \\
\hline$(12-14) \mathrm{min}$. & 0.0490 & & 0.0514 & & 0.0519 & \\
\hline$(0-2)$ min. $\times$ distance to CBD & -0.0060 & $* * *$ & -0.0060 & $* * *$ & -0.0060 & $* * *$ \\
\hline$(2-4) \mathrm{min} . \times$ distance to CBD & -0.0034 & $* * *$ & -0.0033 & $* * *$ & -0.0033 & $* * *$ \\
\hline (4-6) $\mathrm{min} . \times$ distance to CBD & -0.0007 & $*$ & -0.0007 & & -0.0007 & \\
\hline (6-8) $\mathrm{min} . \times$ distance to CBD & 0.0020 & $* * *$ & 0.0020 & $* * *$ & 0.0020 & $* * *$ \\
\hline$(8-10)$ min. $\times$ distance to CBD & -0.0012 & & -0.0011 & & -0.0011 & \\
\hline (10-12) $\mathrm{min} . \times$ distance to CBD & -0.0011 & & -0.0011 & & -0.0010 & \\
\hline$(12-14) \min . \times$ distance to CBD & -0.0016 & & -0.0017 & & -0.0017 & \\
\hline Temporal dummies variables & Yes & & Yes & & Yes & \\
\hline Dynamic spatial effect $(\psi)$ & - & & - & & 0.0215 & $* * *$ \\
\hline Multidirectional spatial effect $(\varrho)$ & - & & 0.0562 & $* * *$ & 0.0443 & $* * *$ \\
\hline $\mathrm{R}^{2}$ & 0.7371 & & 0.7372 & & 0.7373 & \\
\hline LL & 9540.08 & & 9611.39 & & 9619.98 & \\
\hline AIC & $-18,920$ & & $-19,058$ & & $-19,074$ & \\
\hline $\mathrm{BIC}$ & $-18,294$ & & $-18,417$ & & $-18,425$ & \\
\hline $\mathrm{N}_{\mathrm{T}}$ & 18,320 & & 18,320 & & 18,320 & \\
\hline
\end{tabular}

\subsubsection{The North CRT Line}

The difference between the DID, the SDID, and the STDID approaches for the estimate of the north CRT line is less pronounced. This is partly related to the fact that the spatial autoregressive coefficients are lower, even if statistically significant (Table 5). Once again, the pseudo- $R^{2}$ is higher in the STDID model, but the gain is once again marginal, while the AIC and BIC statistics are both lower in the STDID specification. The log-likelihood ratio (LR) test also points in favor of the superiority of the SDID and the STDID models over the DID model (72.10 for the SDID and 83.21 for the STDID). The comparison between the SDID and the STDID is less clear, but the LR test indicates that the STDID model is preferable ( $\mathrm{LR}=10.20)$. Thus, statistically, the STDID model gives, once again, a better global performance. 
Even if the autoregressive coefficients are low, this does not means they make no impact. Here, the estimation results suggest that no effect related to the "on foot" proximity is significant. Moreover, the effect is concentrated for transactions that are located within a 4-min drive, while only houses located within 0 to 2-min drive to the nearest station show a complex relation according to the distance from the CBD. If the marginal effect for houses located between a 2 and 4-min drive from the nearest station is constant over space, the location rent varies for the 0 to 2-min drive depending on the distance to the Montreal CBD. Thus, this effect can also turn out to be quite low for houses located in Saint-Jérôme, about 55 kilometers from the CBD.

Table 5. Estimation results for the north CRT line (green line).

\begin{tabular}{|c|c|c|c|c|c|c|}
\hline \multirow{2}{*}{$\begin{array}{c}\text { Models } \\
\text { Variables }\end{array}$} & \multicolumn{2}{|c|}{ DID Equation (17) } & \multicolumn{2}{|c|}{ SDID Equation (19) } & \multicolumn{2}{|c|}{ STDID Equation (22) } \\
\hline & Coeff. & Sign. & Coeff. & Sign. & Coeff. & Sign. \\
\hline \multicolumn{7}{|l|}{$\Delta$ Sale situation } \\
\hline Forclosure & -0.1160 & $* * *$ & -0.1162 & $* * *$ & -0.1163 & $* * *$ \\
\hline Without legal warranty & -0.0727 & $* * *$ & -0.0726 & $* * *$ & -0.0727 & $* * *$ \\
\hline Succession & -0.0945 & $* * *$ & -0.0900 & $* * *$ & -0.0891 & $* * *$ \\
\hline Transfer & -0.0177 & $* * *$ & -0.0185 & $* * *$ & -0.0186 & $* * *$ \\
\hline \multicolumn{7}{|l|}{$\Delta$ Walking distance } \\
\hline$(0-500) \mathrm{m}$ & 0.0009 & & 0.0024 & & 0.0027 & \\
\hline$(500-1000) \mathrm{m}$ & -0.0182 & & -0.0165 & & -0.0170 & \\
\hline$(1000-1500) \mathrm{m}$ & -0.0035 & & -0.0010 & & -0.0009 & \\
\hline \multicolumn{7}{|l|}{$\Delta$ Driving distance } \\
\hline$(0-2) \mathrm{min}$. & 0.1643 & $* *$ & 0.1589 & $* * *$ & 0.1611 & $* * *$ \\
\hline$(2-4) \mathrm{min}$. & 0.0650 & $*$ & 0.0633 & $*$ & 0.0633 & $*$ \\
\hline$(4-6) \mathrm{min}$. & 0.0431 & & 0.0410 & & 0.0390 & \\
\hline$(6-8) \mathrm{min}$. & 0.0585 & & 0.0553 & & 0.0547 & \\
\hline$(8-10) \mathrm{min}$. & 0.0228 & & 0.0236 & & 0.0230 & \\
\hline$(10-12) \mathrm{min}$. & -0.0566 & & -0.0562 & & -0.0564 & \\
\hline (12-14) $\mathrm{min}$. & 0.0018 & & 0.0013 & & 0.0016 & \\
\hline$(0-2)$ min. $\times$ distance to CBD & -0.0026 & * & -0.0025 & $* *$ & -0.0026 & $* *$ \\
\hline$(2-4) \mathrm{min} . \times$ distance to CBD & -0.0012 & & -0.0012 & & -0.0012 & \\
\hline (4-6) $\min . \times$ distance to CBD & -0.0007 & & -0.0007 & & -0.0006 & \\
\hline$(6-8) \mathrm{min} . \times$ distance to CBD & -0.0009 & & -0.0009 & & -0.0009 & \\
\hline$(8-10) \mathrm{min} . \times$ distance to CBD & -0.0004 & & -0.0004 & & -0.0004 & \\
\hline (10-12) $\min . \times$ distance to CBD & 0,0016 & & 0.0016 & * & 0.0016 & * \\
\hline$(12-14) \mathrm{min} . \times$ distance to CBD & $-0,0001$ & & -0.0001 & & -0.0001 & \\
\hline Temporal dummies variables & Yes & & Yes & & Yes & \\
\hline Dynamic spatial effect $(\psi)$ & - & & - & & 0.0139 & $* *$ \\
\hline Multidirectional spatial effect $(\varrho)$ & - & & 0.0342 & $* * *$ & 0.0273 & $* * *$ \\
\hline $\mathrm{R}^{2}$ & 0.7875 & & 0.7875 & & 0.7876 & \\
\hline LL & $13,126.78$ & & $13,162.83$ & & $13,167.93$ & \\
\hline AIC & $-26,072$ & & $-26,140$ & & $-26,148$ & \\
\hline $\mathrm{BIC}$ & $-25,353$ & & $-25,406$ & & $-25,406$ & \\
\hline $\mathrm{N}_{\mathrm{T}}$ & 19,808 & & 19,808 & & 19,808 & \\
\hline
\end{tabular}

Legend: ${ }^{* * *} p<0.001 ;{ }^{* *} p<0.01 ; * p<0.05$.

\subsubsection{Calculating and Interpreting the Marginal Effect}

Turning our attention to the interpretation of the marginal effect, depending on the specification, yields interesting results. The marginal effect reveals an interesting pattern here, with a higher effect for houses located closer to the CBD, on the south shore and on the north shore, while this effect slowly diminishes with distance to the station, or distance to the CBD.

For the south-east CRT line stations (Table 6), houses located within 0 to 2 min of the nearest CRT station to the CBD (St-Lambert) located about $5 \mathrm{~km}$ from the CBD $\left(\mathrm{d}_{\mathrm{CBD}}=5\right)$, but not within walking 
distance of the station, the DID (in such as case, $\partial \mathbf{y}_{\mathrm{t}} / \partial \mathbf{d}_{0-2 \mathrm{t}}=\beta_{0-2}+\mathrm{d}_{\mathrm{CBD}} \times \beta_{0-2 ; \mathrm{CBD}}$ ) suggests a direct price increase of about $14.45 \%$ (with $\partial \mathrm{y}_{\mathrm{t}} / \partial \mathrm{d}_{0-2 \mathrm{t}}=\beta_{0-2}+\mathrm{d}_{\mathrm{CBD}} \times \beta_{0-2 ;}$ CBD $=0.1774+(5 \times(-0.0066))$ versus $14.71 \%$ for the SDID and $14.72 \%$ for the STDID. Moreover, the spatial spillover effect implies that the total marginal effect is evaluated at $15.58 \%$ for the SDID $\left(\partial \mathbf{y}_{t} / \partial \mathbf{d}_{0-2 t}=\left(\beta_{0-2}+\mathrm{d}_{\mathrm{CBD}} \times \beta_{0-2 \mathrm{CBD}}\right)\right.$ $\left.\times(1-\varrho)^{-1}\right)$ and $15.40 \%$ for the STDID, while the total and final impact for the STDID $\left(\partial \mathbf{y}_{t+\infty} / \partial \mathbf{d}_{0-2 \mathrm{t}}=\right.$ $\left.\left(\beta_{0-2}+\mathrm{d}_{\mathrm{CBD}} \times \beta_{0-2 \mathrm{CBD}}\right) \times[(1-\varrho) \times(1-\psi)]^{-1}\right)$ is estimated at $15.74 \%$ (Table 5). Thus, the total effect is higher by more than 1 percentage point in the STDID than in the DID model.

For houses located within a 0 to 2 min distance of the Mont-St-Hilaire CRT station, and about $40 \mathrm{~km}$ from the CBD, the DID suggests a direct price rise of about $-6.37 \%$, as compared to $-6.43 \%$ for the SDID and $-6.39 \%$ for the STDID. The final total marginal effect is $-6.81 \%$ for the SDID model and $-6.84 \%$ for the STDID. Once again, the impact is higher decomposing the marginal effect to account for the spatial spillover (multidirectional) effect as well as the spatial dynamic (unidirectional) effect, but the gap is of less than half a percentage point in the STDID as compared to the DID model, while it is comparable between SDID and STDID models.

Table 6. Calculation of the marginal effect with the different specifications (south-east line).

\begin{tabular}{|c|c|c|c|c|c|}
\hline Distances & {$[0-2[$ min. $\ddagger$} & {$[2-4[\mathrm{~min}$.} & [4-6[ min. & {$[6-8[\mathrm{~min}$.} & [8-10[ min. \\
\hline \multicolumn{6}{|l|}{ St-Lambert } \\
\hline DID & 0.1445 & 0.1031 & 0.0492 & -0.0046 & 0.0368 \\
\hline SDID & 0.1558 & 0.1073 & 0.0509 & -0.0051 & 0.0377 \\
\hline STDID & 0.1574 & 0.1081 & 0.0517 & -0.0048 & 0.0379 \\
\hline \multicolumn{6}{|l|}{ St-Hubert } \\
\hline DID & 0.0850 & 0.0695 & 0.0419 & 0.0158 & 0.0249 \\
\hline SDID & 0.0919 & 0.0720 & 0.0433 & 0.0162 & 0.0263 \\
\hline STDID & 0.0929 & 0.0727 & 0.0439 & 0.0166 & 0.0265 \\
\hline \multicolumn{6}{|l|}{ St-Bruno } \\
\hline DID & 0.0553 & 0.0528 & 0.0383 & 0.0260 & 0.0190 \\
\hline SDID & 0.0599 & 0.0544 & 0.0395 & 0.0269 & 0.0206 \\
\hline STDID & 0.0607 & 0.0550 & 0.0400 & 0.0274 & 0.0208 \\
\hline \multicolumn{6}{|c|}{ St-Basile-le-Grand } \\
\hline DID & -0.0042 & 0.0192 & 0.0310 & 0.0464 & 0.0072 \\
\hline SDID & -0.0041 & 0.0191 & 0.0318 & 0.0482 & 0.0091 \\
\hline STDID & -0.0039 & 0.0196 & 0.0323 & 0.0488 & 0.0094 \\
\hline \multicolumn{6}{|c|}{ McMasterville } \\
\hline DID & -0.0340 & 0.0024 & 0.0274 & 0.0566 & 0.0013 \\
\hline SDID & -0.0361 & 0.0015 & 0.0280 & 0.0589 & 0.0034 \\
\hline STDID & -0.0361 & 0.0019 & 0.0284 & 0.0595 & 0.0037 \\
\hline \multicolumn{6}{|c|}{ Mont-Saint-Hilaire } \\
\hline DID & -0.0637 & -0.0144 & 0.0237 & 0.0668 & -0.0047 \\
\hline SDID & -0.0681 & -0.0162 & 0.0242 & 0.0695 & -0.0023 \\
\hline STDID & -0.0684 & -0.0158 & 0.0245 & 0.0702 & -0.0020 \\
\hline
\end{tabular}

Legend: ‡ excluding walking accessibility effect.

The difference between the estimation gains is less pronounced on the north-shore (Table 7), with the highest gap between the DID and the STDID being 0.13 percentage points for houses located close to Rosemère station, the first station on the north-shore. However, the relative gain of the STDID model, as compared to the SDID model, accounts for the larger part of this gain. Thus, the introduction of both spatial effects in the model raises interesting gains to evaluate the total gain of the new CRT service, while allowing us to decompose the effect accounting for spatial spillover, but also for the dynamic spatial effect over time. 
Table 7. Calculation of the marginal effect with the different specifications (north line).

\begin{tabular}{|c|c|c|c|c|c|}
\hline Distances & [0-2[ min. $\ddagger$ & [2-4[ min. & [4-6[ min. & [6-8[ min. & [8-10[ $\mathrm{min}$. \\
\hline \multicolumn{6}{|l|}{ Rosemère } \\
\hline DID & 0.0861 & 0.0283 & 0.0213 & 0.0302 & 0.0107 \\
\hline SDID & 0.0864 & 0.0283 & 0.0213 & 0.0304 & 0.0106 \\
\hline STDID & 0.0874 & 0.0285 & 0.0211 & 0.0302 & 0.0105 \\
\hline \multicolumn{6}{|l|}{ Ste-Thérèse } \\
\hline DID & 0.0731 & 0.0222 & 0.0176 & 0.0255 & 0.0086 \\
\hline SDID & 0.0734 & 0.0221 & 0.0178 & 0.0259 & 0.0083 \\
\hline STDID & 0.0740 & 0.0223 & 0.0178 & 0.0258 & 0.0082 \\
\hline \multicolumn{6}{|l|}{ Blainville } \\
\hline DID & 0.0601 & 0.0161 & 0.0140 & 0.0208 & 0.0066 \\
\hline SDID & 0.0604 & 0.0159 & 0.0142 & 0.0215 & 0.0060 \\
\hline STDID & 0.0606 & 0.0160 & 0.0146 & 0.0213 & 0.0060 \\
\hline \multicolumn{6}{|l|}{ St-Jérôme } \\
\hline DID & 0.0210 & -0.0022 & 0.0031 & 0.0067 & 0.0006 \\
\hline SDID & 0.0213 & -0.0027 & 0.0037 & 0.0080 & -0.0009 \\
\hline STDID & 0.0203 & -0.0027 & 0.0048 & 0.0079 & -0.0008 \\
\hline
\end{tabular}

Legend: ‡ excluding walking accessibility effect.

\subsection{Discussion}

The demonstration in the case of house transactions and price appreciation (or the price determination process) is a good example of how it is possible to decompose the marginal effect, not only accounting for the indirect and total spatial spillover effect, but also accounting for a unidirectional (dynamic) spatial effect. The latest effect allows us to account for the temporal decomposition of the marginal effects accounting for the short-term and long-term impacts of the spatial multidirectional spillover effect. This decomposition is similar to what is done in the spatial panel case, but the application here lies on a totally different type of data: spatial data pooled over time, i.e., individual spatial data that are treated as different observations over time.

Thus, opting for a DID estimator necessarily implies that we can observe at least a given observation (house) twice. However, single observations are seldom repeated more than twice over a decade, let alone more. Moreover, since the sale implies different actors- the first buyer now being the seller, while a first seller and a second buyer are different economic agents-these observations may be viewed as separate observations, while being in the same spatial location. Thus, opting for the DID, SDID, or STDID estimators implies dealing with pairs of observations, but these pairs can be seen as individual spatial data pooled over time.

To our knowledge, this is the first attempt to calculate the short- and long-term marginal effect for spatial data pooled over time. This implies extending the SDID estimator, as developed by [31], to incorporate two types of spatial effect: (i) a multidirectional effect, which is the usual spatial spillover effect, i.e., the spatial effect for a given time period; and (ii) a unidirectional effect, which is equivalent to a temporal effect, but locally measured. The inclusion of these two effects gives a STDID estimator and allows us to decompose the marginal effect according to the spatial spillover effect, as well as a short- and long-term spillover effect.

In the end, the paper shows how it is possible to account for separate effects in an STDID approach with spatial data pooled over time. Although the difference between the DID and the STDID does not appear great at first glance, even so calculation of the marginal effects shows how, even for low values of the autoregressive parameters, this effect can be important in the long run. Of course, as the spatial autoregressive parameters are low, the difference between the estimation of the effect obtained through a DID, a SDID, or a STDID approach decrease and may even converge to the same values. However, 
the only situation in which the estimation results will be equal is when the spatial autoregressive parameters are not statistically different from zero (0).

Translating individual effects into global effects by considering the full total housing stock over time can represent a huge difference, even if the individual difference is about half a percentage point. Considering the fact that some houses have been sold for more than \$CAN 1 million and that many of these transactions have occurred, the total economic impact of implementing a new mass transit system could easily be underestimated $[29,30]$. Translated on the full housing stock, a gain of one percentage point difference can represent a large total economic impact. For example, [29] estimate that taxing the total gain for proximity to a CRT station can easily pay for the full operating cost of the service within a given year. For this reason, we think that the decomposition of the spatial effects and the calculation of the marginal effects accounting for both spatial effects can be a useful framework for future analysis of the impact of public policy using spatial data pooled over time.

\section{Conclusions}

The paper proposes developing a spatio-temporal difference-in-differences (STDID) estimator to account for two separate effects in the calculation of the marginal effect of an exogenous change in environmental amenities: (i) a spatial multidirectional effect; and (ii) a spatial unidirectional effect. Taking into account those two effects, the paper shows how one can take into account these two spatial dimensions in the calculation of the marginal effects, and how such effects may change the global portrait of the calculation of the economic impact of landscaping policies on real estate prices. The STDID allows us to decompose the effect to incorporate spatial spillover effects, but also shortand long-term dynamic spatial effects.

The originality of this paper is twofold. First, it is the first time that such a framework has been applied to spatial data pooled over time, and it is the first time that the calculation of the marginal effects has been discussed for such a database. The calculation of the marginal effects using row-standardized weights matrices and equivalence results and proof from previous study, lead us to propose a simple way to calculate marginal effects. This framework can be used by scholars for future applications and enable the use of complicated matrix calculations: the marginal effects are calculated using the parameters (scalars) only. Second, the model developed in first-difference on real estate transactions is a direct application of a spatio-temporal difference-in-differences (STDID) estimator, which is a natural extension of the spatial difference-in-differences (SDID) proposed by [31].

To illustrate the calculation of the marginal effect, an empirical case related to change in mass transit supply, more specifically on a commuter rail train (CRT), is investigated. The results show how ignoring the spatial spillover effect can underestimate the total marginal effect and influence the total economic impact. The importance of the indirect marginal spatial spillover effect and the short- and long-term effects are directly related to the size of the autoregressive coefficients. Thus, even if, in the actual applications, the coefficients remain quite low ( $\varrho$ and $\psi<0.05)$, the interpretation nevertheless shows how these coefficients can have a global influence on the calculation, for example, of the economic benefits of a new mass transit supply.

In the end, we hope that this work will guide future interpretations about the estimation of the possible impact of changes in public policies when dealing with spatial data pooled over time. The precision and the richness of what can be said when the effects are decomposed according to their spatial dimension, but also their temporal dimension is a clear contribution of this paper. Addressing the complex spillover effect of landscaping and planning public policies is a real challenge that can be addressed using the development proposed in this paper.

Acknowledgments: This research was funded by the Agence Métropolitaine de Transport (AMT) in Montreal and undertaken through JDMD Groupe conseils inc., an independent consulting firm based in Québec City and Rimouski. The authors would like to thanks the Altus Group for allowing us to use their database on single family houses sold in the Montréal area between 1992 and 2009 as well as the Canadian real Estate Association of Canada (CREA). 
Author Contributions: Jean Dubé, Marius Thériault and François Des Rosiers conceived and designed the experiments; Jean Dubé, Diègos Legros and Marius Thériault performed the experiments; Jean Dubé, Diègos Legros and Marius Thériaultanalyzed the data; Jean Dubé and Diègos Legros contributed reagents/materials/analysis tools; Jean Dubé wrote the paper.

Conflicts of Interest: The authors declare no conflict of interest.

\section{References}

1. Rosen, S. Hedonic Prices and Implicit Markets: Product Differentiation in Pure Competition. J. Political Econ. 1974, 82, 34-55. [CrossRef]

2. Krige, D.G. Two-dimensional Weighted Moving Average Trend Surfaces for Ore Valuation. J. S. Afr. Inst. Min. Metall. 1966, 67, 13-38.

3. Trigg, D.W.; Leach, A.G. Exponential Smoothing with an Adaptive Response Rate. J. Oper. Res. Soc. 1967, 18, 53-59. [CrossRef]

4. Widrow, B.; Hoff, M.E. Adaptive Switching Circuits. In 1960 IRE WESCON Convention Record, Part 4; Institute of Radio Engineers: New York, NY, USA, 1960; pp. 96-104.

5. Casetti, E. The Expension Method, Mathematical Modeling, and Spatial Econometrics. Int. Reg. Sci. Rev. 1997, 20, 9-33. [CrossRef]

6. Casetti, E. Generating Models by Extension Method: Applications to Geographical Research. Geogr. Anal. 1972, 4, 81-91. [CrossRef]

7. Cleveland, W.S.; Devlin, S.J. Locally Weighted Regression: An Approach to Regression Analysis by Local Fitting. J. Am. Stat. Assoc. 1988, 83, 596-610. [CrossRef]

8. Fotheringham, A.S.; Brunsdon, C.; Charlton, M.E. Geographically Weighted Regression: The Analysis of Spatially Varying Relationships; Wiley: London, UK, 2002.

9. Fotheringham, A.S.; Charlton, M.E.; Brunsdon, C. Geographically Weighted Regression: A Natural Evolution of the Expansion Method for Spatial Data Analysis. Environ. Plan. A 1998, 30, 1905-1927. [CrossRef]

10. McMillen, D.P. One Hundred Fifty Years of Land Values in Chicago: A Nonparametric Approach. J. Urban Econ. 1996, 40, 100-124. [CrossRef]

11. Ord, K. Estimation Methods for Models of Spatial Interaction. J. Am. Stat. Assoc. 1975, 70, 169-184. [CrossRef]

12. Anselin, L. Spatial Econometrics: Methods and Models; Kluwer Academic: Dodrecht, The Netherlands, 1988.

13. Dubin, R.A.; Pace, R.K.; Thibodeau, T.G. Spatial Autoregression Techniques for Real Estate Data. J. Real Estate Lit. 1999, 7, 79-96. [CrossRef]

14. LeSage, J.P.; Pace, R.K. Advanced in Econometrics; Elsevier: Oxford, UK, 2004; Volume 18.

15. Anselin, L.; Griffith, D.A. Do Spatial Effects Really Matter in Regression Analysis. Pap. Reg. Sci. Assoc. 1988, 65, 11-34. [CrossRef]

16. LeSage, J.P.; Pace, R.K. Introduction to Spatial Econometrics; CRC Press: New York, NY, USA, 2009.

17. LeSage, J.P. An Introduction to Spatial Econometrics. Revue D'économie Industrielle 2008, 123, 19-44. [CrossRef]

18. LeSage, J.P. Pitfalls in Higher Order Model Extensions of Basic Spatial Regression Methodology. Rev. Reg. Stud. 2011, 41, 13-26.

19. Overman, H.G. Making an Impact: Misreading, Misunderstanding, and Misrepresenting Research does Nothing to Improve the Quality of Public Debate Making. Environ. Plan. A 2014, 46, 2276-2282. [CrossRef]

20. Corrado, L.; Fingleton, B. Where is the Economics in Spatial Econometrics? J. Reg. Sci. 2012, 52, $210-239$. [CrossRef]

21. Gibbons, S.; Overman, H.G. Mostly Pointless Spatial Econometrics? J. Reg. Sci. 2012, 52, 172-191. [CrossRef]

22. LeSage, J.P.; Pace, R.K. The Biggest Myth in Spatial Econometrics. Econometrics 2014, 2, 217-249. [CrossRef]

23. Thanos, S.; Dubé, J.; Legros, D. Putting Time into Space: Establishing the Coherence of Spatial Applications in the Housing Market. Reg. Sci. Urban Econ. 2016, 58, 78-88. [CrossRef]

24. Dubé, J.; Legros, D. Spatial Econometrics Using Microdata; John Wiley \& Sons: London, UK, 2014; p. 242.

25. Dubé, J.; Legros, D. Dealing with Spatial Data Pooled over Time in Statistical Models. Lett. Spat. Resour. Sci. 2013, 6, 1-18. [CrossRef]

26. Smith, T.E.; Wu, P. A Spatio-temporal Model of Housing Prices based on Individual Sales Transactions over Time. J. Geogr. Syst. 2009, 11, 333-355. [CrossRef] 
27. Pace, R.K.; Barry, R.; Clapp, J.M.; Rodriquez, M. Spatiotemporal Autoregressive Models of Neighborhood Effects. J. Real Estate Financ. Econ. 1998, 17, 15-33. [CrossRef]

28. Dubé, J.; Legros, D. Spatial Econometrics and the Hedonic Pricing Model: What about the Temporal Dimension? J. Prop. Res. 2014, 31, 333-359. [CrossRef]

29. Dubé, J.; Thériault, M.; Des Rosiers, F. Commuter Rail Accessibility and House Values: The Case of the Montréal South Shore, Canada, 1992-2009. Transp. Res. Part A 2013, 54, 49-66. [CrossRef]

30. Dubé, J.; Des Rosiers, F.; Thériault, M.; Dib, P. Economic Impact of a Supply Change in Mass Transit in Urban Areas: A Canadian Example. Transp. Res. Part A 2011, 45, 46-62. [CrossRef]

31. Dubé, J.; Legros, D.; Thériault, M.; Des Rosiers, F. A Spatial Difference-in-Differences Estimator to Evaluate the Effect of Change in Public Mass Transit Systems on House Prices. Transp. Res. Part B, 2014, 64, 24-40. [CrossRef]

32. McMillen, D.P. Issues in spatial data analysis. J. Reg. Sci. 2010, 50, 119-141. [CrossRef]

33. Greene, W.H. Econometric Analysis, 7th ed.; Prentice Hall: Upper Saddle River, NJ, USA, 2012.

34. Wooldridge, J.M. Econometric Analysis of Cross Section and Panel Data; MIT Press: Cambridge, MA, USA, 2001.

35. Wooldridge, J.M. Introductory Econometrics: A Modern Approach; South-Western College Publishing: Cincinnati, OH, USA, 2000; p. 824.

36. McMillen, D.P. Perspectives on Spatial Econometrics: Linear Smoothing with Structured Models. J. Reg. Sci. 2012, 52, 192-209. [CrossRef]

37. LeSage, J.P. What Regional Scientists Need to Know about Spatial Econometrics. Rev. Reg. Stud. 2014, 44, 13-32. [CrossRef]

38. Vega, S.H.; Elhorst, J.P. The SLX Model. J. Reg. Sci. 2015, 55, 339-363. [CrossRef]

39. Abreu, M.; De Groot, H.L.F.; Florax, R.J.G.M. Space Growth: A Survey of Empirical Evidence Methods. Régions et Développement 2005, 21, 13-44. [CrossRef]

40. Small, K.A.; Steimetz, S.S.C. Spatial Hedonics and the Willingness to Pay for Residential Amenities. J. Reg. Sci. 2012, 52, 635-647. [CrossRef]

41. Steimetz, S.S.C. Spatial Multipliers in Hedonic Analysis: A Comment on "Spatial Hedonic Models of Airport Noise, Proximity, and Housing Prices". J. Reg. Sci. 2010, 50, 995-998. [CrossRef]

42. Kim, C.W.; Phipps, T.T.; Anselin, L. Measuring the Benefits of Air Quality Improvement: A Spatial Hedonic Approach. J. Environ. Econ. Manag. 2003, 45, 24-39. [CrossRef]

43. Dubé, J.; Legros, D. Spatial Econometrics and Spatial Data Pooled over Time: Towards an Adapted Modelling Approach. J. Real Estate Lit. 2014, 22, 101-125.

44. Dubé, J.; Legros, D. A Spatio-temporal Measure of Spatial Dependence: An Example Using Real Estate Data. Pap. Reg. Sci. 2013, 92, 19-30. [CrossRef]

45. Bailey, M.J.; Muth, R.F.; Nourse, H.O. A Regression Method for Real Estate Price Index Construction. J. Am. Stat. Assoc. 1963, 58, 933-942. [CrossRef]

46. Case, K.E.; Shiller, R.J. The Efficiency of the Market for Single-Family Homes. Am. Econ. Rev. 1989, 79, 125-137.

47. Case, K.E.; Shiller, R.J. Prices of Single-Family Homes since 1970: New Indexes for Four Cities. N. Engl. Econ. Rev. 1987. [CrossRef]

48. Clapp, J.; Giaccotto, C. Estimating Price Trends for Residential Property: A Comparison of Repeat Sale and Assessed Value Methods. J. Am. Stat. Assoc. 1992, 87, 300-306. [CrossRef]

49. Ciuna, M.; De Ruggiero, M.; Salvo, F. Property Prices Index Numbers and Derived Indices. Prop. Manag. 2014, 32, 139-153.

50. Heckman, J. Sample Selection Bias as a Specification Error. Econometrica 1979, 47, 153-161. [CrossRef]

51. Heckman, J. The Common Structure of Statiscal Models Truncation, Sample Selection and Limited Dependent Variables and a Simple Estimator for Such Models. Ann. Econ. Soc. Meas. 1976, 5, 475-492.

52. Gibbons, S.; Machin, S. Valuing School Quality, Better Transport, and Lower Crime: Evidence from House Prices. Oxf. Rev. Econ. Policy 2008, 24, 99-119. [CrossRef]

53. Can, A.; Megbolugbe, I. Spatial Dependence and House Price Index Construction. J. Real Estate Financ. Econ. 1997, 14, 203-222. [CrossRef]

54. Chagas, A.; Azzoni, C.; Almeida, A. A Spatial Difference-in-Differences Analysis to Measure the Sugarcane Producing Impact on Respiratory Health. In Proceedings of the European Regional Science Association, Lisbon, Portugal, 25-28 August 2015. 
55. Delgado, M.S.; Florax, F.J.G.M. Differnce-in-Differences Techniques for Spatial Data: Local Autocorrelation and Spatial Interaction. Econ. Lett. 2015, 137, 123-126. [CrossRef]

56. Sunak, Y.; Madlener, R. Local Impact of Wind Farms on Property Values: A Spatial Difference-in-Differences Analysis. Internatl. Assoc. Energ. Econ. 2014. [CrossRef]

57. Heckert, M. A Spatial Difference-in-Differences Approach to Studying the Effect of Greening Vacant Land on Property Values. Cityscape 2015, 17, 51-59.

(c) (1)

(c) 2017 by the authors. Licensee MDPI, Basel, Switzerland. This article is an open access article distributed under the terms and conditions of the Creative Commons Attribution (CC BY) license (http://creativecommons.org/licenses/by/4.0/). 